Article

\title{
Design of an Integrated Heat Dissipation Mechanism for a Quad Transmit Receive Module of Array Radar
}

\author{
Jian-Yi Liang ${ }^{1, *}$, Yung-Lung Lee ${ }^{2}$, Shih-Wei Mao ${ }^{3}\left(\mathbb{D}\right.$ and Ming-Da Tsai ${ }^{4}$ \\ 1 School of Defense Science, Chung Cheng Institute of Technology, National Defense University, \\ Taoyuan City 335009, Taiwan \\ 2 Department of Power Vehicle and Systems Engineering, Chung Cheng Institute of Technology, \\ National Defense University, Taoyuan City 335009, Taiwan; yunglunglee84@gmail.com \\ 3 Department of Mechanical Engineering, ROC Military Academy, Kaohsiung City 830208, Taiwan; \\ swmao1@gmail.com \\ 4 Department of Environmental Information and Engineering, Chung Cheng Institute of Technology, \\ National Defense, Taoyuan City 335009, Taiwan; tsai.md5478@ccit.ndu.edu.tw \\ * Correspondence: ke20051005@yahoo.com.tw; Tel.: +886-3380-0627
}

check for updates

Citation: Liang, J.-Y.; Lee, Y.-L.; Mao, S.-W.; Tsai, M.-D. Design of an Integrated Heat Dissipation Mechanism for a Quad Transmit Receive Module of Array Radar. Appl. Sci. 2021, 11, 7054. https://doi.org/ 10.3390/app11157054

Academic Editor: Nicola Bianco

Received: 10 June 2021

Accepted: 27 July 2021

Published: 30 July 2021

Publisher's Note: MDPI stays neutral with regard to jurisdictional claims in published maps and institutional affiliations.

Copyright: (c) 2021 by the authors. Licensee MDPI, Basel, Switzerland. This article is an open access article distributed under the terms and conditions of the Creative Commons Attribution (CC BY) license (https:// creativecommons.org/licenses/by/ $4.0 /)$.

\begin{abstract}
A radar system requires a number of high-power components operating in a narrow and convection-free environment. This study aims to develop an integrated heat dissipation system that is suitable for the high-power electronic equipment of radar systems. The proposed heat dissipation mechanism integrates a fluid circulation-type cold plate with a quad transmit receive module. The finite element method in the COMSOL fluid-solid coupling heat transfer analysis software was used to analyze the heat dissipation performance of the cold plate in the proposed mechanism. The Taguchi method was adopted to optimize the cold plate design. The simulation and experimental results show that the proposed mechanism can control the temperature equalization and temperature of the system within the specified requirements. The practicality of the proposed mechanism was verified. The findings can serve as a reference for the design of high-power electronic equipment in a heat dissipation system.
\end{abstract}

Keywords: cold plate heat sink; liquid impingement; quad transmit/receive module; integrated heat dissipation system; Taguchi analysis method

\section{Introduction}

After one hundred years of development, radar technology has undergone multiple evolutions and is achieving increasingly higher system performances. Compared with the continuous innovations of stealth technology, radar technology has also made new progress. Among them, phase array radar may track targets within a radar cross-sectional area of less than $0.01 \mathrm{~m}^{2}$ and has been widely used in large ground-to-air defense radar and small airborne radar. Nowadays, phase array radar is developing towards high-power Active Electronic Scanning Arrays (AESA), as the performance requirements of national defense weapon systems continue to increase, meaning that their miniaturization and multifunctioning have become the basic performance items required by contemporary radar systems. With the increasing number of electronic components used in a radar system and the increasing demand for the operating power, a large number of high-power components must operate in a narrow, closed, and convection-free environment. Without a proper heat dissipation mechanism, the internal temperature of the system will rise sharply, which may damage the electronic components, thus affecting the reliability of the system. In other words, a high-performance heat dissipation mechanism is vital for ensuring the normal operation of the system and improving its work efficiency, and it is also a key technology for the effective operation of contemporary weapon systems.

Communication and electronic equipment technologies have developed rapidly, and the operating power of electronic modules has continuously increased. However, the 
product volume has gradually decreased. This has resulted in a steep rise in heat or non-uniform temperature distribution in the system, failing functions, or degraded performances. Therefore, the performance of heat sinking has become a very important key technology in the research and development of electronic equipment. With the improving efficiency of electronic modules, the traditional heat sinking method can no longer meet the requirements of the systems for high power or high heat flux; thus, it is unable to maintain the safe operating temperature of the chips. In order to solve the above problem, high-performance cooling schemes, such as air cooling, liquid cooling, and Phase-Change Materials (PCMs), have been developed and studied. The advantage of a liquid cooling system is that the liquid has a much higher thermal conductivity than air and a better heat transfer stability than PCM. Liquid cooling methods include direct/indirect liquid cooling, liquid-vapor phase cooling, and vertical liquid jet impingement cooling [1,2]. A liquid cooling system should have a good cooling capacity, but it requires multiple parts with complete functions, including key parts and components such as cold plates, heat exchangers, fans, pumps, and water tanks. Therefore, the challenges involving such a system include complexity, high cost, and potential liquid leak problems.

A cold plate performs heat sinking by indirect contact between the heat source and the cooling fluid. It is a feasible scheme for high heat flux electronic modules and it has been extensively used in military and commercial electronic devices. In the case of press-pack and high-power operations, the cooling performance of a cold plate is the key factor in an electronic system's performance, and so the optimal design of a cold plate is of great importance [1]. A cold plate is generally composed of hollow channels that can be installed on the surface of an electronic heat source and that allow the coolant to flow through it, so as to reach the required cooling rate. In addition, single-phase forced convection enhancement techniques (e.g., the jet impingement technique and the multidomain modeling framework) are used for quick cooling [1-4]. The cooling performance of a cold plate can be improved and enhanced by the special configuration design of the coolant flow channel, such as the fin structures, serpentine-channel configuration, micro-channel and porous structures (tetrakaidecahedron-like unit cell structures), and the Rhombi-Octet unit cell. The topics of how to enhance cooling efficiency by a splitter design and the adoption of cooling fluid (e.g., water, glycol solution, silicone oil, nano fluids) have been discussed in related studies [1,2,4-36].

The aforementioned high heat transfer liquid cooling technique (cold plate) is generally used in the thermal management system of electronic power modules, such as the engine of new generation electric vehicles, electromotors and robots, and for newgeneration communication and telecommunication systems. The radio frequency of a high-performance millimeter wave Transmit/Receive (T/R) antenna module transfers high-power pulse signals to the antenna by converting electricity into high-power electromagnetic wave signals. When the energy of the power amplifier of the power equipment increases continuously, the electronic equipment needs to be cooled down and maintained by a high heat transfer liquid cooling system, at a safe temperature, so as to maximize the efficiency and stability of the equipment.

Wiriyasart et al. simulated a cold plate with liquid impinging jet flow to analyze the cooling performance under configurations of fins in different geometric shapes and working fluids [1]. Their 3D model, based on a single-phase or two-phase flow, can visualize the temperature distribution of the cold plate and fluid flow behavior, and analyze the influences of heat flux, the mass flow rate of the coolant, as well as the heat source area on thermal resistance. Their findings showed that the input power, the coolant mass flow rate, the heat source area, the geometric shape of the fins, and the coolant type have significant impacts on the overall thermal performance of the cold plate heat sink.

In terms of experimental validation, some studies used the jet impingement technique to design a cooling performance test platform, and liquid impinging cold plates of different fin shapes (conical, circular, and rectangular) to test their thermal diffusion [2]. The experimental results showed that the fin shape of a cold plate affects the overall thermal 
resistance, and that a circular fin has a better cooling performance. The experimental results are helpful for analyzing the cooling performance, the thermal resistance, and the spreading resistance of a cold plate heat sink for electronic products.

Zhang et al. [3] employed multi-domain modeling architecture to analyze the cooling performance of a cold plate of a $6 \mathrm{~s} 4 \mathrm{p}$ (six batteries connected in series and four batteries connected in parallel, in one interval) lithium ion battery and obtained a high discharge rate and temperature change in an external short circuit period. They thus proposed a cold plate design strategy with special channels for adjusting the coolant state. Xu et al. [5] designed fins in the straight channels of a liquid cold plate to simulate the thermal equilibrium performance of a liquid cooling system. They studied five splitter structure parameters, including the number of fins, the length, the angle and the distance between two fins, as well as the offset distance. The simulation results showed that the mean temperature difference decreases as the number of fins increases and that the fin deflection angle and length have a considerable influence on the thermal equilibrium.

Deng et al. [6,7] designed and built a 3D model aluminum alloy cold plate with a U-tube serpentine channel structure and different channel layouts, and discussed the influence of the number of cold plates, the number and layout of the cooling channels, as well as the coolant inlet temperature, the mass flow rate, and the direction on the cooling performance. The simulation results showed that the influence of the number of channels and inlet temperature on the cooling performance has an upper limit, that the maximum temperature of the cooling system rises with the coolant inlet temperature, and that the cooling performance is limited by the mass flow rate and direction of the coolant. Jarrett et al. [8,9] designed an optimal rectangular channel cold plate and studied the influence of different operating conditions on its cooling performance. The results showed that the optimum values of objective functions, such as the pressure drop, average temperature, and temperature uniformity, cannot be obtained at the same time, and that the temperature uniformity is most likely influenced by the working conditions, especially the inlet heat flux and the mass flow rate of the coolant.

Huo et al. [10] built a 3D heat sinking model of a microchannel cold plate with straight channels. The simulation results showed that the most extreme temperature drops occur as the number of channels and inlet mass flow rate increases. In addition, when the inlet mass flow rate increases, the influence of the flow direction on the cooling performance decreases, and the improvement of the cooling effect is less obvious as the inlet mass flow rate increases. Cova et al. [11-13] effectively used Computational Fluid Dynamics (CFD) for the analysis and optimal design of an aluminum cold plate and proposed the SPICECFD/FEM method for the optimal design of a water radiator for high-power systems. Their findings showed that the cold plate cooling performance is the key with which to power electronic systems. When designing a stable heat sink from multiple aspects, a simulation analysis and the construction of experimental equipment come at a high cost. This method has a negligible simulation cost. In addition, there must be a balance between the thickness, the cooling performance, and the fluid pressure drop in the design of a cold plate. Such a modeling method is significantly effective and consistent for the optimum design of an aluminum cold plate.

In terms of research on the influence of the coolant composition on the cooling performance, Cao et al. [14] experimentally compared the cooling performance of water and the Nano Phase Change Material Emulsion (NPCME) cooling liquid, at different melting temperatures and concentrations, and built a microchannel cold plate hard product with a U-tube serpentine channel structure. The results showed that if the inlet temperature is lower than, or close to, the melting point, then the NPCME has a better cooling effect than water. NPCME also has a higher specific heat capacity than water and is free from supercooling. It can achieve the cooling performance of water with a lower pumping power.

In terms the influence of the structure and materials of a cold plate on its cooling performance, Li et al. [15] studied a copper tube, coupled with a silicon cold plate-based thermal management system. The experimental results showed that the combination of 
a silicon cold plate and a copper tube could absorb heat rapidly, and could effectively transfer it to the water in the cold plate channels, resulting in a better cooling performance. In their research on the cold plate of a microchannel with multiple internal channels, Zhang et al. [16] found that it can take the heat out of the system, which results in a good heat transfer performance.

Yu et al. [37] found that the plate thickness and tube spacing are the key factors in the cooling capacity of a cold plate. Wang et al. [38] found that a cold plate could be used in the heat shield of a high temperature heat source, and analyzed the influence of the inlet volume flow rate, the number of flow channels, and the channel thickness on the heat source. Some studies adopted the Additive Manufactured (AM) technology [4,17-25,30-36,39], which can effectively design and manufacture metal objects with highly complex geometric shapes, to customize and build high-performance heat transfer units in a confined space. AM technology and material properties can also consider the weaker structural properties induced by a lower metal content in the material. The structural strength of the materials of the parts and components manufactured by AM can be enhanced by a complex heat treatment process, but the post-process is time consuming and costly.

As observed from previous studies, the cold plate can be used in high-performance and high-power cooling systems. In addition, to reduce the development costs, CFD and Finite Element Method (FEM) software, including ANSYS, COMSOL, and FloEFD software, can be used for the simulation analysis. In addition, if the shape of the cold plate hard product is too complex, then it can be manufactured by using advanced AM technology. In order to develop an integrated heat dissipation system that is suitable for high-power electronic equipment, where the size and weight of the system are limited, this study integrated a fluid circulation-type cold plate structure with a T/R module. Additionally, it adopted the optimal design of the liquid flow channel inside the cold plate and the active heat dissipation assembly of the thermoelectric cooler. The FEM was used as the COMSOL fluid-solid coupling heat transfer analysis software for the structure to analyze the heat dissipation performance of the proposed fluid circulation-type cold plate. The Taguchi method was used to optimize the designed fluid circulation-type cold plate. According to the simulation and experimental validation results, the proposed integrated heat dissipation mechanism can control the temperature equalization of the system within the specified requirements. The system can operate under the energysaving and performance specifications and requirements. Moreover, the effectiveness and practicality of the heat dissipation mechanism proposed in this paper can be verified, and a reference can be provided for the design of high-power electronic equipment in a heat dissipation system.

\section{System Architecture and Problem Description}

\subsection{Architecture of the Integrated Heat Dissipation Module}

Based on AESA radar, a high-performance heat dissipation system is designed with a limited size and weight. The heat dissipation mechanism of the whole system is composed of two sub-systems, namely, the Integrated Heat Dissipation Module (IHDM) and the Heat Exchange Module (HEM), as shown in Figure 1. The phase array radar T/R module, which is the subject of this study, is designed as the Quad Transmit Receive Module (QTRM). The heat exchanger of these modules cools the coolant flowing into the heat exchanger and transmits the heat energy outside of the system, while the pump provides the flow power of the fluid circulation. The $\mathrm{T} / \mathrm{R}$ module is the main heat-source-generating module of the system (shown in the red area in Figure 1). Since each T/R module is composed of several arranged electronic components, the temperature difference between each electronic component must be maintained within a certain range, to ensure the consistent operational function of each electronic component. Therefore, it is necessary to control the heat dissipation of the cold plate by the heat dissipation assembly in order to maintain the overall operating temperature of the $\mathrm{T} / \mathrm{R}$ module within an appropriate range, which is also the purpose of this study. In order to meet the requirements of effective 
heat dissipation for high-power modules in a narrow space, this study combined the fluid circulation-type cold plate and the phase array radar $\mathrm{T} / \mathrm{R}$ module to develop an integrated heat transfer module, and it then optimized its design. The operational mode of the whole system uses the pump to pressurize the coolant in the storage tank and sends it out to the fluid pipeline (Cool-out); it then adjusts the flow rate through the throttle, so that the cold water (Cool-in) flowing into the four cold plates can maintain a uniform speed and volume, and the coolant flowing into the cold plates can be used to dissipate heat to the $\mathrm{T} / \mathrm{R}$ module. The coolant absorbs heat energy inside the cold plate, then flows out through the hot water outlet (Hot-out), and is guided to the hot water inlet (Hot-in) of the heat exchanger through a pipeline, where the hot water is cooled by the heat exchanger, thus forming an active high-performance circulating heat dissipation system.

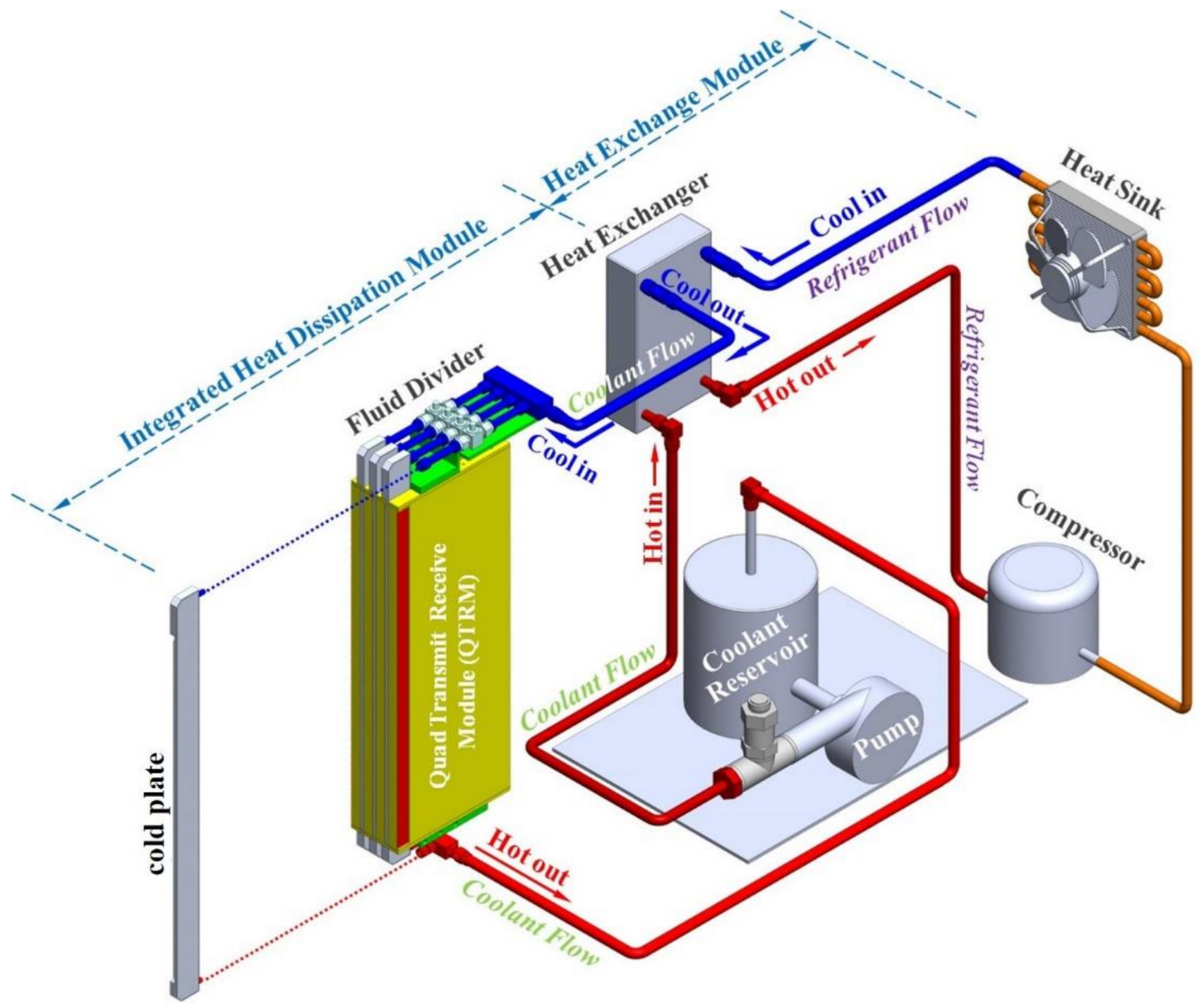

Figure 1. Fluid circulation heat dissipation system.

The above-mentioned sub-system components all play an important role in the heat dissipation mechanism of the overall system, and the design of the IHDM is a vital and key module that affects the heat dissipation performance of the whole system. Among them, the temperature equalization and heat dissipation performance of the fluid circulation-type cold plate are the key components that directly affect the performance of the radar system. Therefore, this study focused on the optimal design of the fluid circulation-type cold 
plate so that the radar system components can operate within an appropriate temperature variation range, which ensures that the radar can perform its expected functions.

\subsection{Optimal Design of the Fluid Circulation-Type Cold Plate}

A cold plate is generally composed of hollow channels, which are installed on the heat-dissipating surface of an electronic heat source and allow the coolant to flow through, so as to reach the required cooling rate. The cold plate uses a single-phase indirect liquid cooling technique, and acts as the main interface when the heat source fails to contact the coolant fluid directly [4]. A schematic diagram of the operating principle of the fluid circulation-type cold plate can be found in Figure 2. Although the sintered cold plate has the advantage of being a good heat conductor, it comes at a high cost and only has the function of temperature equalization, which means that it cannot conduct the heat energy from inside the cold plate to the outside. In addition to the temperature equalization function, the fluid circulation-type cold plate can be used to remove its internal heat energy. Its working principle is to contact the fluid with the internal heat dissipation fin (Internal feature) and remove the heat energy generated by the heat source from the cold plate, as shown in Figure 2. According to the operational principle of the fluid circulation-type cold plate, the design parameters, such as the size and shape of the internal fins, the flow rate, and temperature of the fluid, will affect its heat dissipation performance. This study employed the Taguchi analysis method to optimize the design parameters of the fluid circulation-type cold plate.

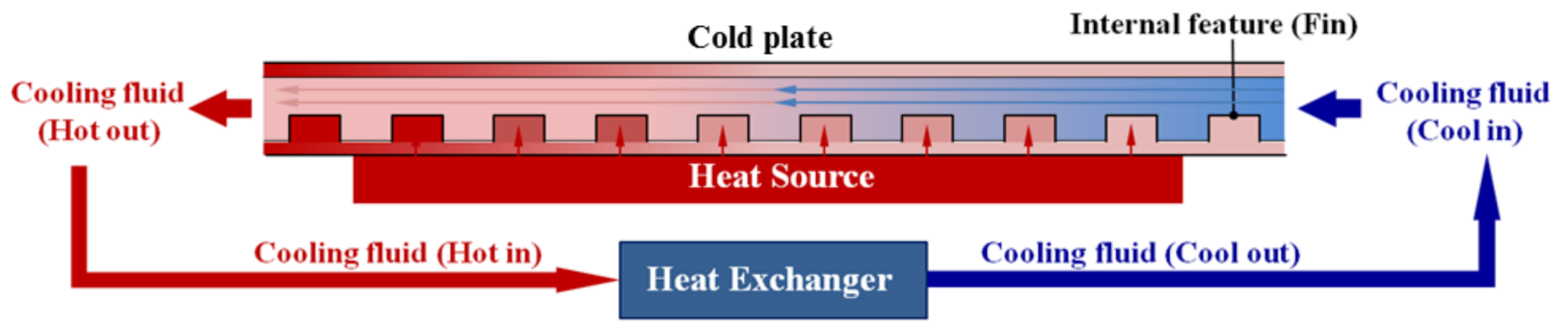

Figure 2. Schematic diagram of the operation principle of fluid circulation-type cold plate.

\section{Design and System Description of the Cold Plate}

This study used the SolidWorks 3D drawing software to design three kinds of internal fins with different sizes and shape characteristics for the fluid circulation-type cold plate. Considering the flow rate and temperature of the internal fluid when the heat source power was $210 \mathrm{~W}$, the conjugate heat transfer module of the COMSOL simulation software was adopted to simulate the heat conduction efficiency of different fin configurations for the fluid circulation-type cold plate. The Taguchi analysis method was used to determine the optimal design parameters, considering various factors, such as the temperature, the flow rate of the cooling fluid, the size and appearance characteristics of the internal fins, the distribution quantity, and the volume size of internal fins.

Based on the size and weight specifications of the T/R module of airborne AESA radars, this study designed a fluid circulation-type cold plate that can match the size of the $\mathrm{T} / \mathrm{R}$ module, which means that it can fit with the $\mathrm{T} / \mathrm{R}$ module to form an integrated heat dissipation module. The outer dimensions of the cold plate are as follows: length: $622 \mathrm{~mm} \times$ width: $40 \mathrm{~mm} \times$ thickness: $12 \mathrm{~mm}$; and the internal dimensions are: length: $518 \mathrm{~mm} \times$ width: $36 \mathrm{~mm} \times$ thickness: $4 \mathrm{~mm}$, as shown in Figure 3. In addition, according to the size of the inner and outer spaces of the cold plate, three types of fins, namely, square fins (Type I), round fins (Type II) and finless fins (Type III), were designed and modeled using the SolidWorks 3D drawing software. While they have different shapes, Type I and II fins have the same surface area, the same number of fins (462), and the same center distance between the adjacent fins, as shown in Figure 3. 


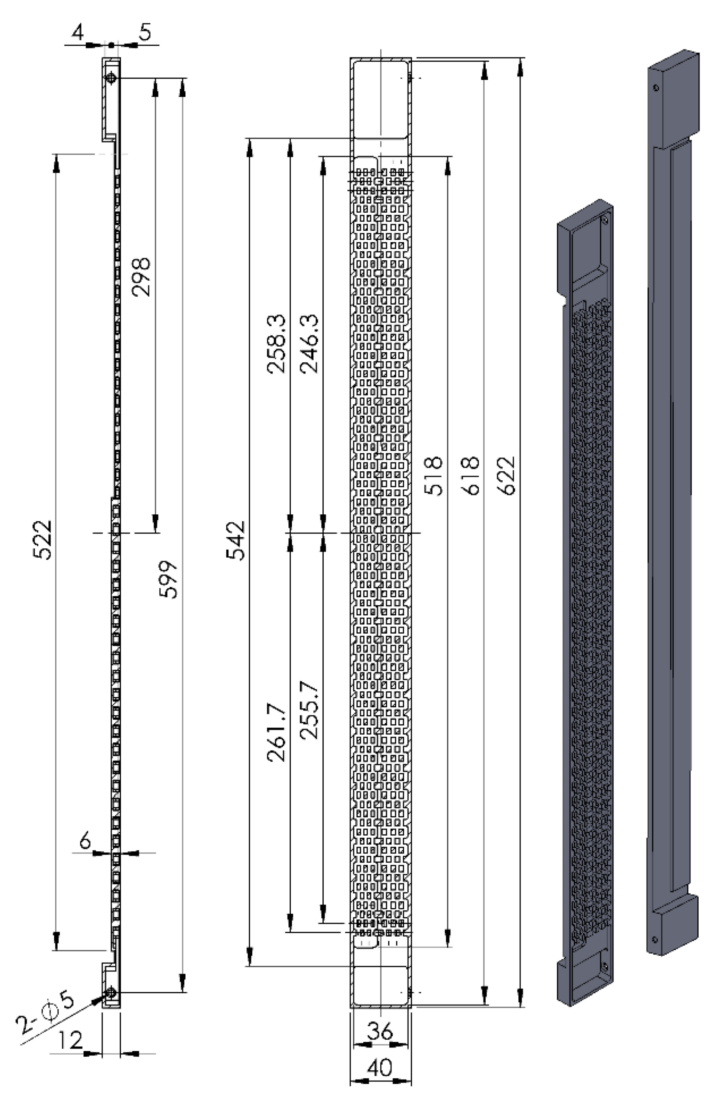

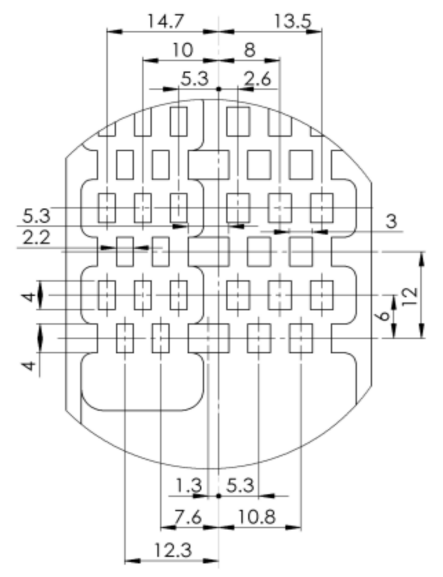

Type I

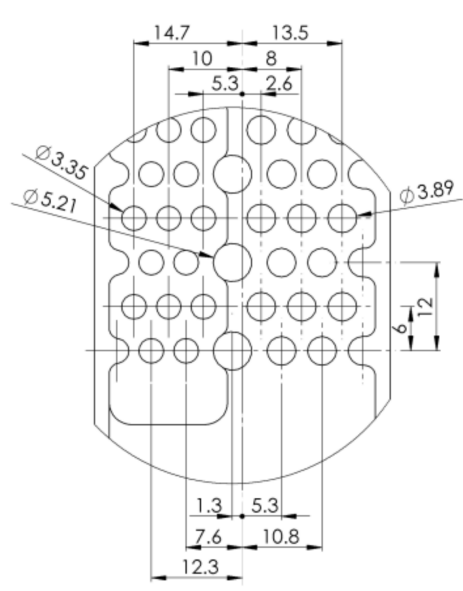

Type II

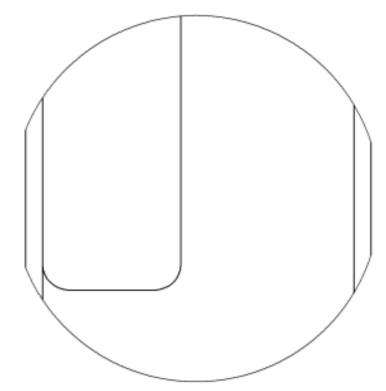

Type III

Figure 3. Design drawing of the internal and external configuration of a three-dimensional cold plate.

\section{Optimal Design of the Heat Dissipation Performance of the Fluid Cold Plate}

Before optimizing the design of the internal fins of the cold plate, in order to provide a reference basis for the subsequent parameter optimization design, it is necessary to understand the basic heat dissipation performance of the three design types of cold plates in advance. This paper analyzed the basic heat dissipation performances of the three types of cold plates, namely, Types I, II, and III.

\subsection{Mesh System Design}

This study used the finite element analysis software, COMSOL, to simulate the heat dissipation phenomenon of the fluid circulation-type cold plate. The design of this mesh system can distinguish the coolant fluid mesh system and the cold plate structure mesh system, which is created by Solidwork drawing software, and then it is imported into the COMSOL software. In this work, the mesh elements are automatically generated by the built-in mesh element generator of the COMSOL software according to the user-defined mesh element shape (triangular mesh selected in this article), the number of mesh elements, and the cold plate configuration. After setting the relevant parameters, the mesh elements are automatically generated by the software, as shown in Figures 4-6. The space between the two adjacent fins inside the cold plate is the flow passage of the cooling fluid. The heat source of the T/R module is distributed between 250 and $-280 \mathrm{~mm}$ at the coordinate position of the cold plate. The mesh elements of the three types of cold plates designed in this study are Type I, with 331,622 mesh elements, Type II, with 344,164 mesh elements, and Type III, with 209,780 mesh elements. 


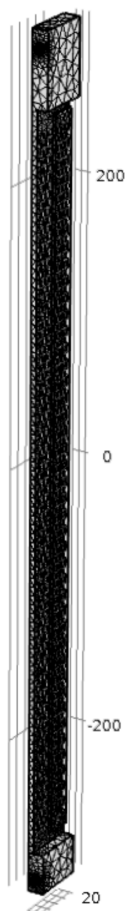

(a) Full scale

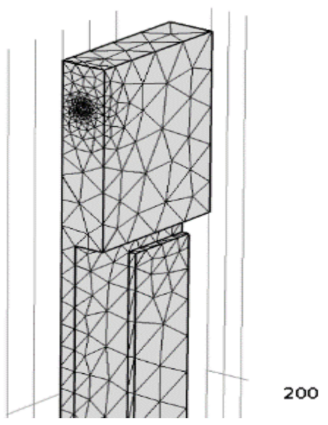

(b) Enlarged view of the upper end

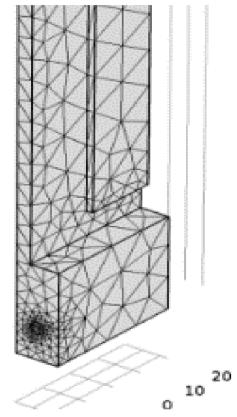

(c) Enlarged view of the lower end

Figure 4. External meshes of the cold plate.

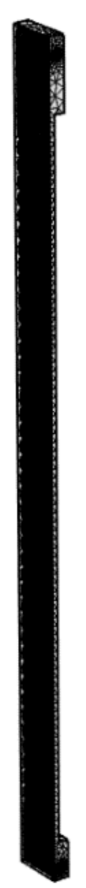

(a) Full scale

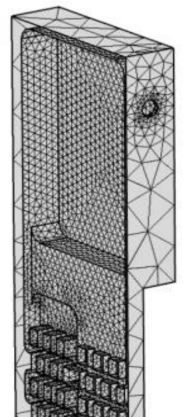

Type I

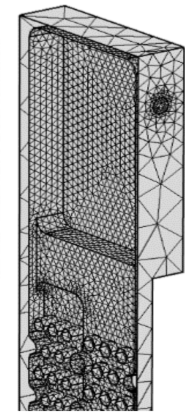

Type II

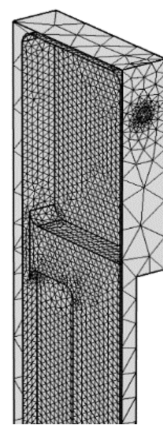

Type III (b) Enlarged view of the upper end

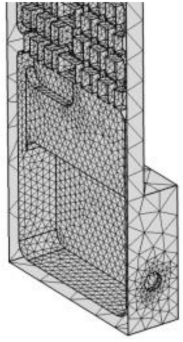

Type I

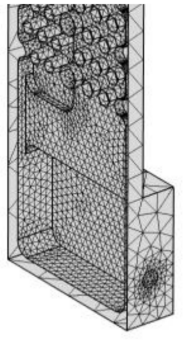

Type II

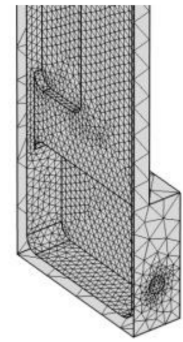

Type III

(c) Enlarged view of the lower end

Figure 5. Internal meshes of the cold plate with fins of different configurations. 


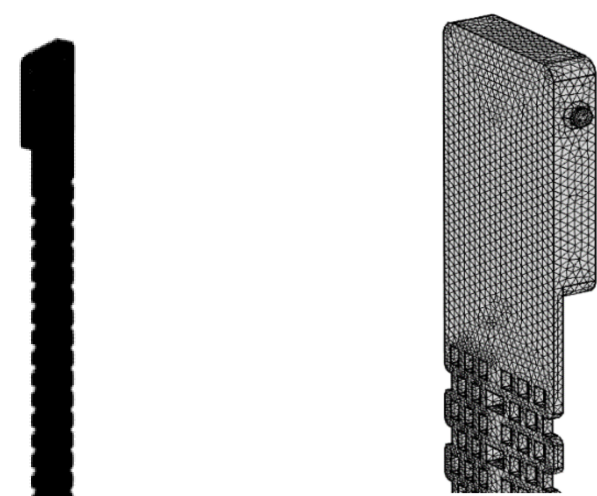

Type I

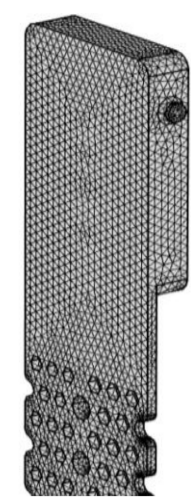

Type II

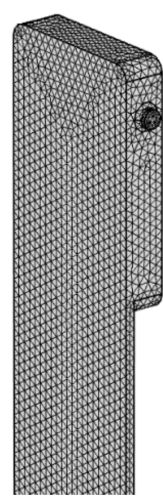

Type III

(b) Enlarged view of the upper end
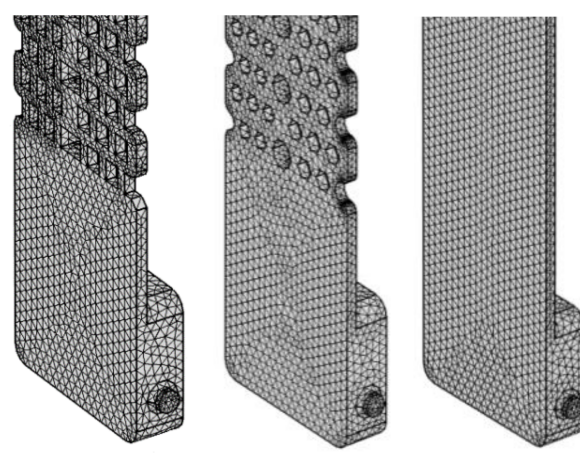

Type I

Type II

Type III

(c) Enlarged view of the lower end

Figure 6. Fluid meshes.

\subsection{Simulation Results and Analysis}

In this study, the fluid inflow and outflow cold plates are set to flow into the upper end and out from the lower end, as shown in Figure 7. As the coolant fluid in electronic components must be non-conductive, a fluorinated liquid with non-toxic, pollution-free, non-conductive, volatile, and other characteristics was selected as the coolant in this study, and the simulation parameters are shown in Table 1. The subject of this article is the X-band GaN PA MMIC phased array radar system. The operating power of this system is $210 \mathrm{~W}$, so we use $210 \mathrm{~W}$ for simulation. Based on the simulation results, the temperature and pressure distribution of the fluid inside the cold plate and the temperature distribution of the cold plate were analyzed, and then the basic heat dissipation performances of the designed Type I, II, and III cold plates were discussed. Figure 8 shows the simulation results of the temperature responses of the coolant fluid, cold plate structure, heat source surface and internal pressure of the cold plate in Types I, II and III when the system is in a steady state. The upper part of Figure 8a shows the temperature distribution of the coolant fluid, and the lower part shows the temperature change of the coolant fluid from the inlet $(-298 \mathrm{~mm})$ to the outlet $(298 \mathrm{~mm})$ (A-A cross section). The upper part of Figure 8b shows the temperature distribution of the cold plate, and the lower part shows the temperature change of the cold plate from the upper end $(-311 \mathrm{~mm})$ to the lower end $(311 \mathrm{~mm})(B-B$ cross section). The upper part of Figure $8 \mathrm{c}$ shows the temperature distribution of the heat source surface, and the lower part shows the temperature change from the upper end $(-246.3 \mathrm{~mm})$ to the lower end $(255.7 \mathrm{~mm})$ (C-C cross section) of the heat source contact surface. The upper part of Figure 8d shows the internal pressure distribution of the cold plate, and the lower part shows the internal pressure change of the cold plate from the inlet $(-298 \mathrm{~mm})$ to the outlet $(298 \mathrm{~mm})$ (D-D cross section). Table 2 shows the difference between 
the inlet and the outlet of each state according to the simulation results. From Table 2, we can see that compared to Type II and Type III, the square internal fins (Type I) have the smallest temperature difference in fluid, cold plate or heat source surface, which indicates that Type I has better temperature equalization. Moreover, the highest temperature of Type I is also the lowest among the three cold plates, which proves that Type I has a better heat dissipation performance. It is also known that the fluid pressure difference at the outlet/inlet position of Type I is the largest of these three cold plates. This phenomenon is due to the strong vortex effect when the fluid flows through the square fin, which will slow down the fluid and generate a large pressure difference. Due to the pressure increase of the cooling fluid inside the cold plate, it has a better heat conduction performance. The results show that the fluid vortex effect, as generated by the internal fins, will affect the heat transfer performance of the cold plate.
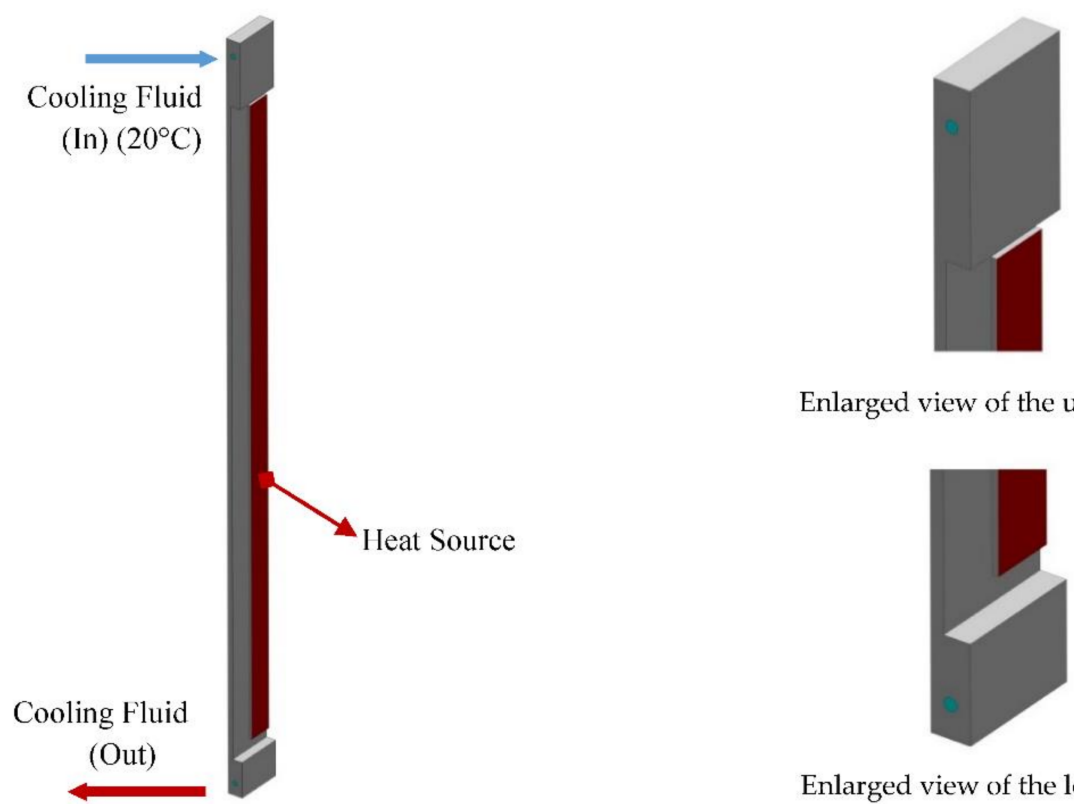

Enlarged view of the upper end

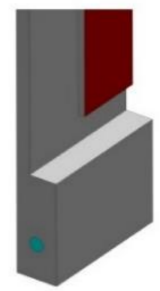

Enlarged view of the lower end

Figure 7. Three-dimensional cold plate heat source and fluid inlet/outlet position.

Table 1. Simulation parameters of the heat dissipation of a three-dimensional cold plate.

\begin{tabular}{cccccc}
\hline & \multicolumn{2}{c}{ Fluid Condition } & \multicolumn{2}{c}{ Heat Transfer Condition } \\
\hline No. & Item & Parameter/Condition & No. & Item & Parameter/Condition \\
\hline 1 & Fluid pattern & Turbulent flow & 1 & Material & Aluminum alloy \\
\hline 2 & $\begin{array}{c}\text { Fluid } \\
\text { material }\end{array}$ & Fluorinated liquid & 2 & $\begin{array}{c}\text { Thermal } \\
\text { conductivity }\end{array}$ & $155 \mathrm{~W} / \mathrm{mK}$ \\
\hline 3 & $\begin{array}{c}\text { Inlet flow } \\
\text { velocity }\end{array}$ & $5 \mathrm{~m} / \mathrm{s}$ & 3 & Heat source & $210 \mathrm{~W}$ \\
\hline 5 & $\begin{array}{c}\text { Fluid inlet } \\
\text { temperature }\end{array}$ & $20^{\circ} \mathrm{C}$ & 4 & $\begin{array}{c}\text { Boundary } \\
\text { condition }\end{array}$ & Natural convection \\
\hline 5 & $\begin{array}{c}\text { Ambient } \\
\text { temperature }\end{array}$ & $25^{\circ} \mathrm{C}$ & 5 & $\begin{array}{c}\text { Ambient } \\
\text { temperature }\end{array}$ & $25^{\circ} \mathrm{C}$ \\
\hline 6 & $\begin{array}{c}\text { Outlet } \\
\text { Pressure }\end{array}$ & $0 \mathrm{~Pa}$ & & & \\
\hline
\end{tabular}



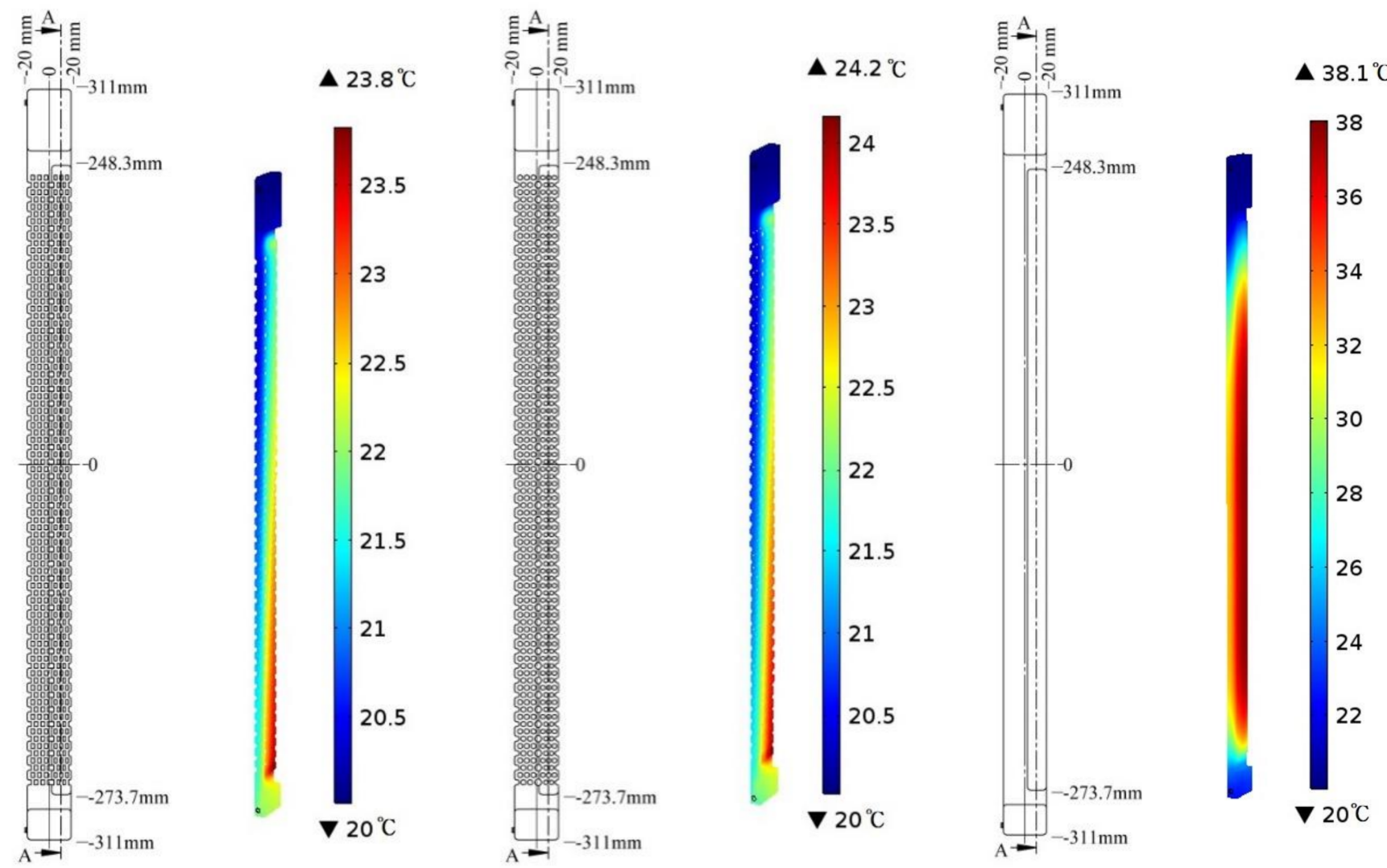

Type I

Type II

Type III

$\left({ }^{\circ} \mathrm{C}\right)$

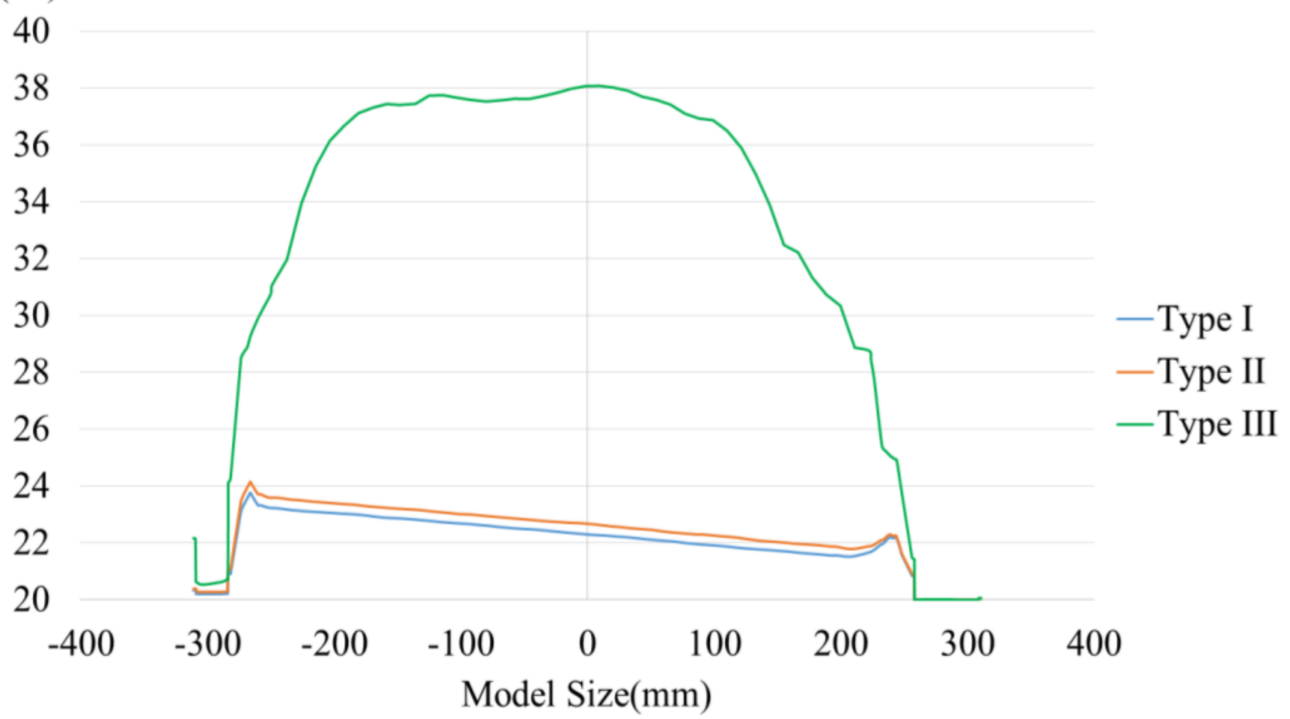

(a) Fluid temperature distribution

Figure 8. Cont. 

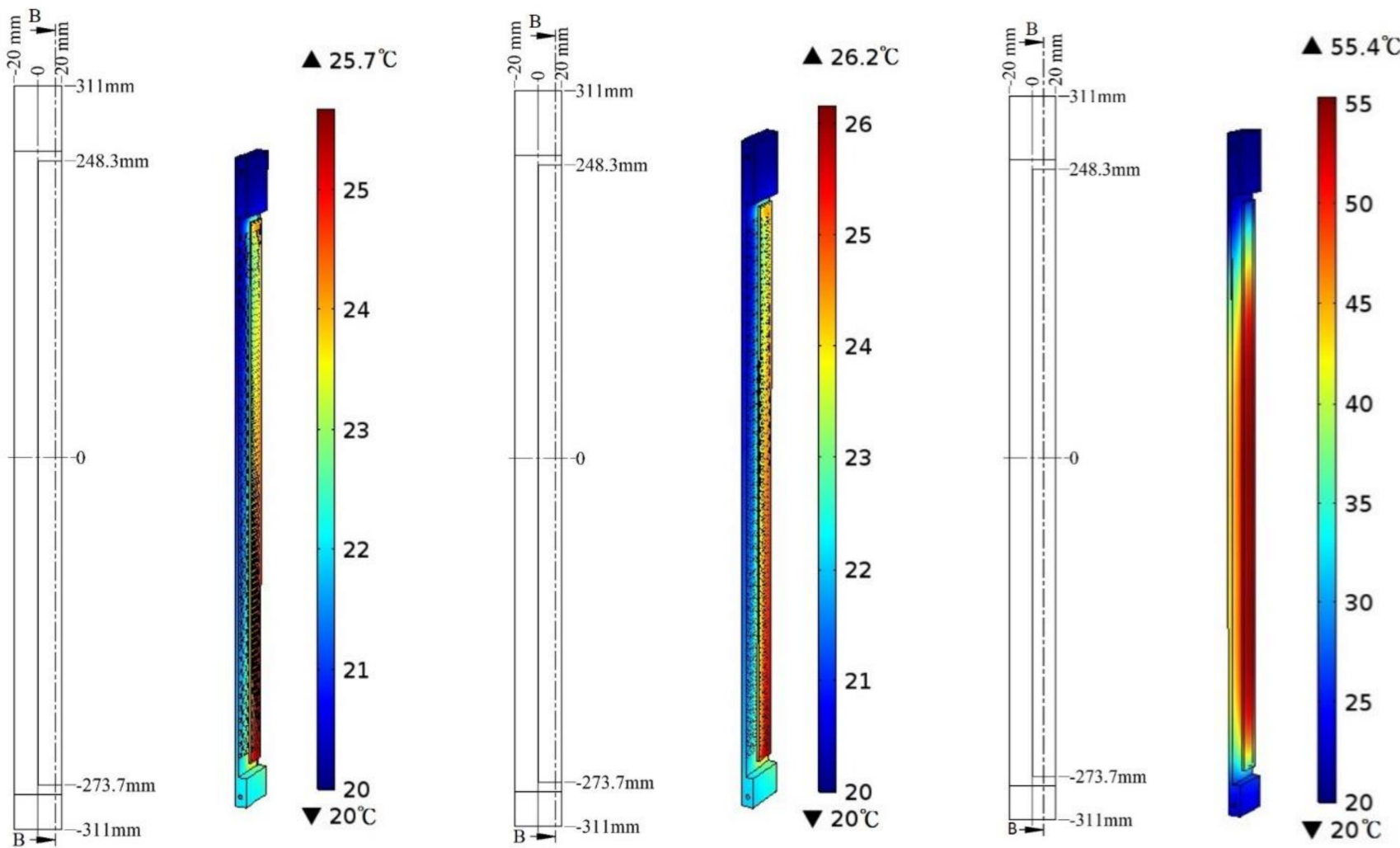

Type I

Type II

Type III

$\left({ }^{\circ} \mathrm{C}\right)$

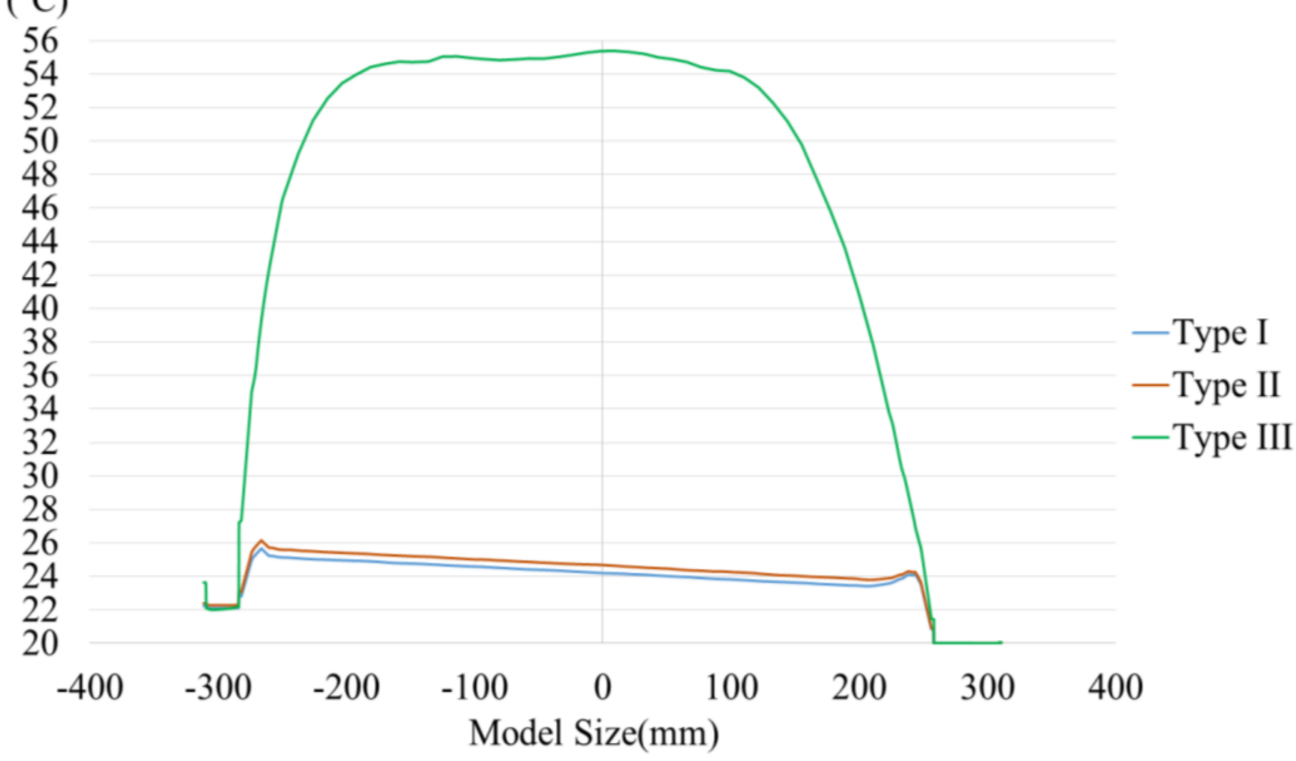

(b) Temperature distribution of the cold plate

Figure 8. Cont. 

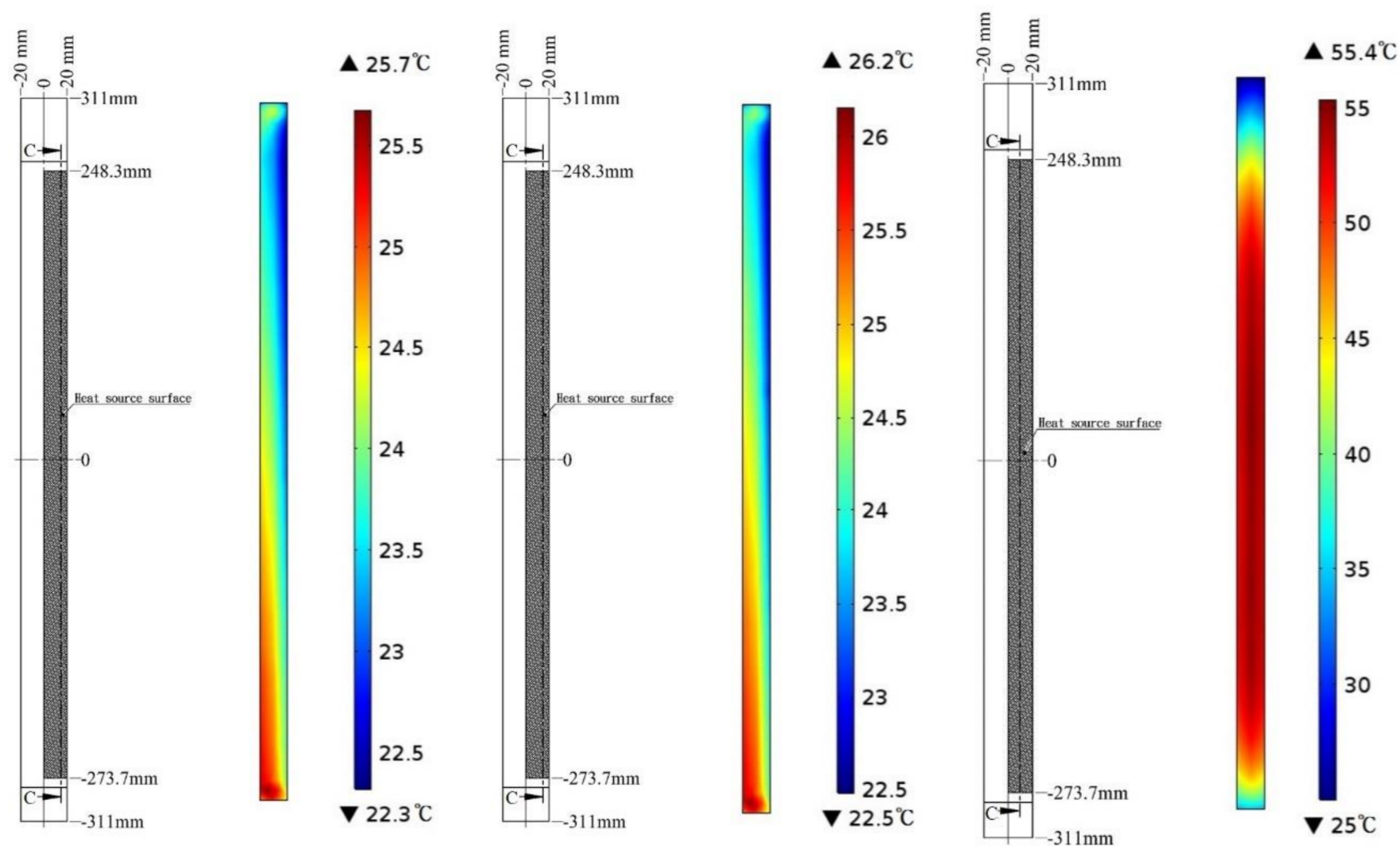

Type I

Type II

Type III

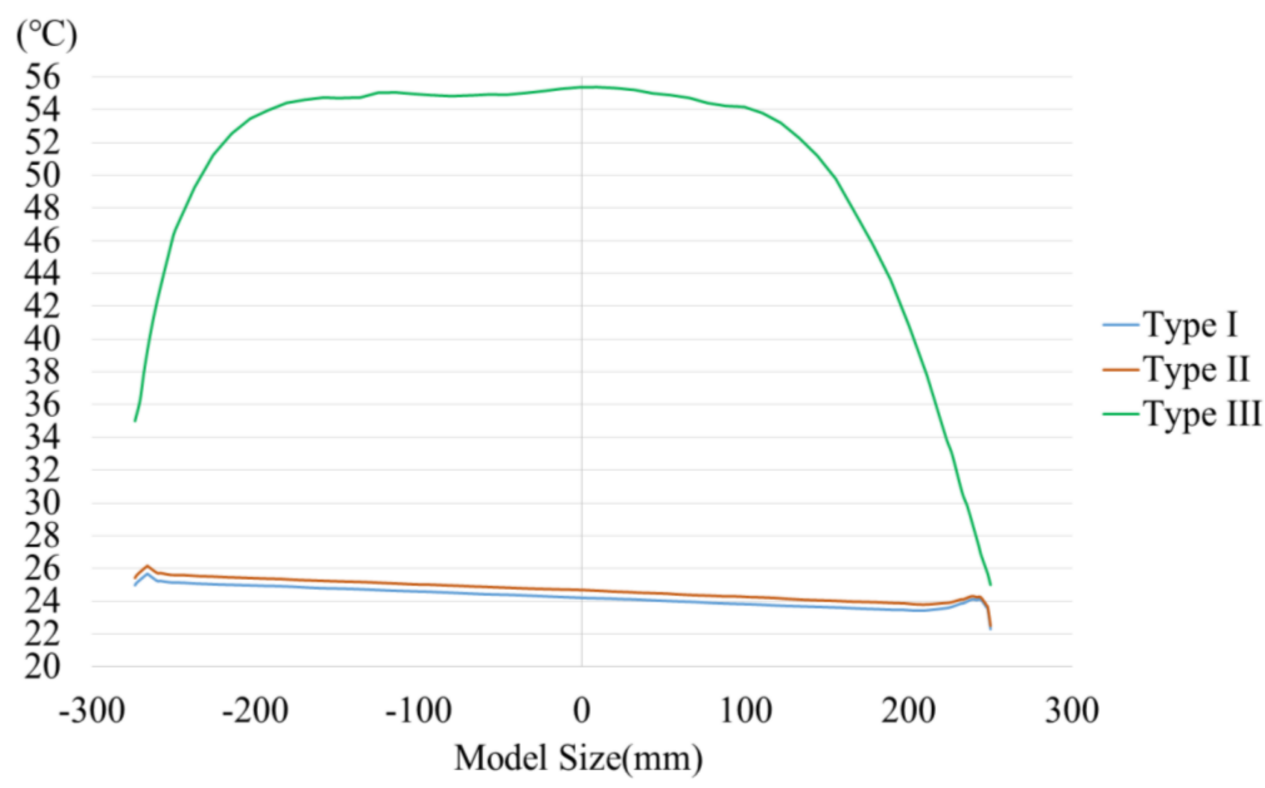

(c) Temperature distribution on the heat source surface

Figure 8. Cont. 


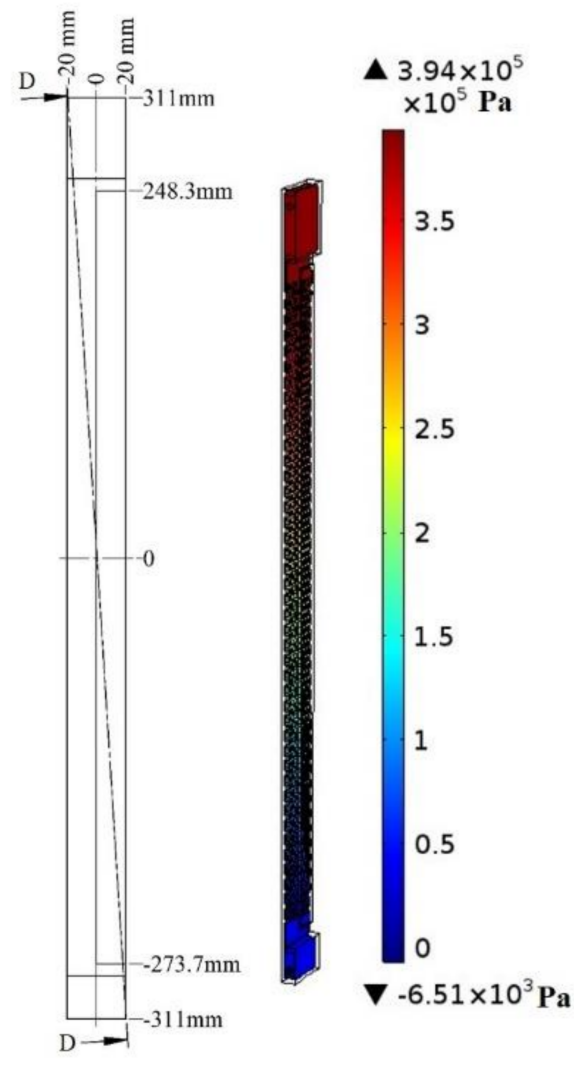

Type I
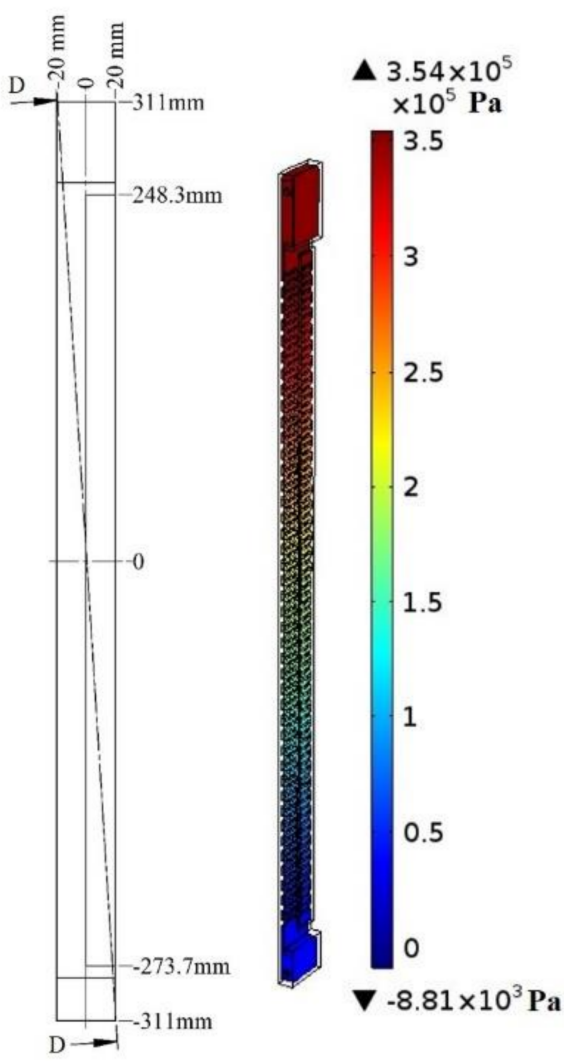

Type II
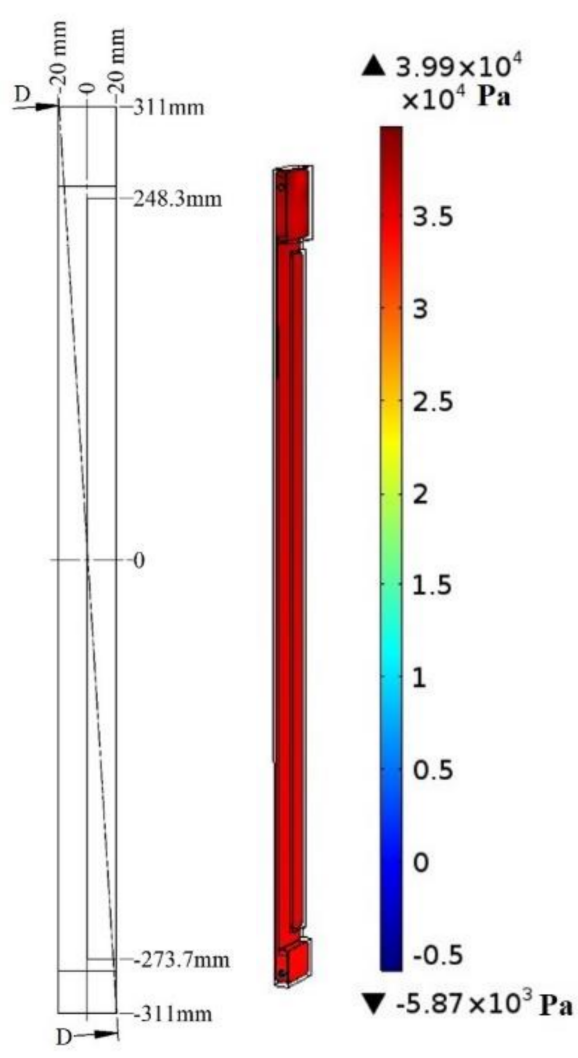

$\mathrm{Pa}$

Type III

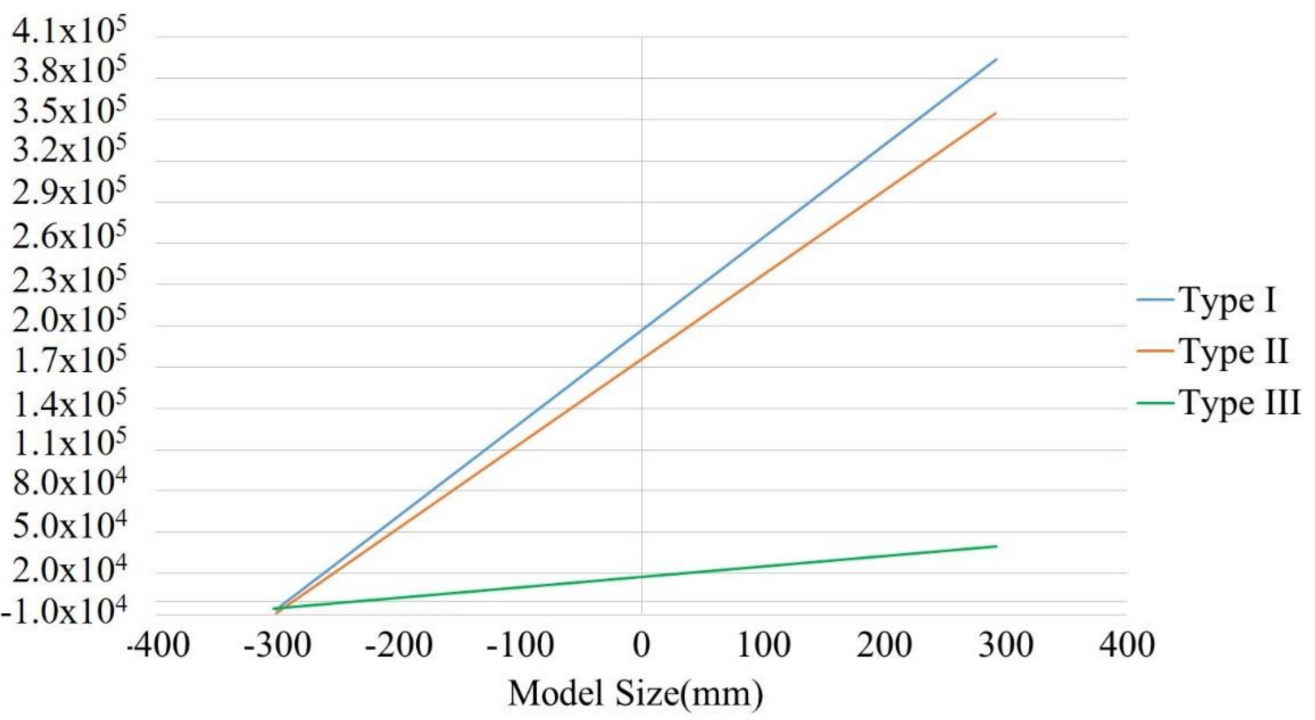

(d) Fluid pressure distribution

Figure 8. Simulation results of the fluid cold plate. 
Table 2. Comparison of outlet and inlet position status differences.

\begin{tabular}{cccccc}
\hline & $\begin{array}{c}\text { Fluid Temperature } \\
\text { Difference } \\
\left({ }^{\circ} \mathbf{C}\right)\end{array}$ & $\begin{array}{c}\text { Temperature Difference } \\
\text { of Cold Plate } \\
\left({ }^{\circ} \mathbf{C}\right)\end{array}$ & $\begin{array}{c}\text { Heat Source Surface } \\
\text { Temperature } \\
\text { Difference } \\
\left({ }^{\circ} \mathbf{C}\right)\end{array}$ & $\begin{array}{c}\text { Fluid Velocity } \\
\text { Difference } \\
(\mathbf{m} / \mathbf{s})\end{array}$ & $\begin{array}{c}\text { Pressure Difference } \\
\left(\mathbf{k g f} / \mathbf{c m}^{2}\right)\end{array}$ \\
\hline Type I & 3.8 & 5.7 & 3.4 & 6.221 & 6.079 \\
\hline Type II & 4.2 & 6.2 & 3.7 & 6.174 & 3.705 \\
\hline Type III & 18.1 & 35.4 & 30.4 & 6.140 & 0.467 \\
\hline
\end{tabular}

\subsection{Optimizing the System Performance of the Parameter Design}

According to the simulation results of the basic performance of the cold plate in Section 4.2, the temperature equalization performances of Types I and II are similar, and because the circular fin does not have the advantage of improving the heat dissipation performance and it is difficult to manufacture, it is difficult to popularize and apply. Based on the simulation conditions and the design parameters of Type I, the optimal design of the Type I cold plate was carried out in this study. Where the central position and number of square fins are unchanged, the fluid volume inside the cold plate was changed by changing the size of the fins, and the temperature equalization of the heat source surface of the cold plate was analyzed. As (A) the volume of the coolant fluid inside the cold plate, (B) the inlet speed of the coolant fluid, (C) the initial temperature of the coolant, and (D) the diameter of the inlet are all important design parameters that affect the heat dissipation performance of the cold plate, they were used as the control factors in this study. As the inlet diameter is limited by the system size and cannot be adjusted again, it is set to a certain value $(\mathrm{D}=4 \mathrm{~mm})$. This study used the L9 $\left(3^{4}\right)$ Taguchi method, in which each factor has three levels, as shown in Table 3. The temperature and temperature difference on the heat source surface shown in Table 4 are the results obtained by numerical simulation according to the nine groups of de-sign parameters of the orthogonal arrays table. According to the design parameters of L1 L9, the distribution of temperature, the internal fluid temperature, the fluid velocity, and the pressure of the cold plate, as obtained by simulation, are shown in Figure 9.

Table 3. L9 $\left(3^{4}\right)$ factor level table.

\begin{tabular}{rrrccc}
\hline \hline Factor & Level & $\mathbf{1}$ & $\mathbf{2}$ & $\mathbf{3}$ & $59,446.72$ \\
\hline $\mathrm{A}$ & Flow volume $\left(\mathrm{mm}^{3}\right)$ & $62,470.72$ & $60,958.72$ & 5 \\
\hline $\mathrm{B}$ & Flow velocity $(\mathrm{m} / \mathrm{s})$ & 3 & 4 & 25 \\
\hline $\mathrm{C}$ & Initial coolant temperature $\left({ }^{\circ} \mathrm{C}\right)$ & 15 & 20 & 4 \\
\hline
\end{tabular}

Table 4. Comparison of the heat dissipation performance of different design parameters (orthogonal arrays).

\begin{tabular}{ccccccc}
\hline Exp. & A & B & C & D & Heat Source Surface Temperature $\left({ }^{\circ} \mathbf{C}\right)$ & $\begin{array}{c}\text { Heat Source Surface } \\
\text { Temperature Equalization }\left({ }^{\circ} \mathbf{C}\right)\end{array}$ \\
\hline 1 & 1 & 1 & 1 & 1 & $19.1-23.6$ & 4.5 \\
2 & 1 & 2 & 2 & 2 & $23.2-26.9$ & 3.7 \\
3 & $\mathbf{1}$ & 3 & 3 & 3 & $27.7-30.7$ & 3.0 \\
4 & 2 & 1 & 2 & 3 & $24.1-28.5$ & 4.4 \\
5 & 2 & 2 & 3 & 1 & $28.2-31.9$ & 3.7 \\
6 & 2 & 3 & 1 & 2 & $17.6-21$ & 3.4 \\
7 & 3 & 1 & 3 & 2 & $28.5-33.1$ & 4.6 \\
8 & 3 & 2 & 1 & 3 & $17.8-21.7$ & 3.9 \\
9 & 3 & 3 & 2 & 1 & $22.3-25.7$ & 3.4 \\
\hline
\end{tabular}




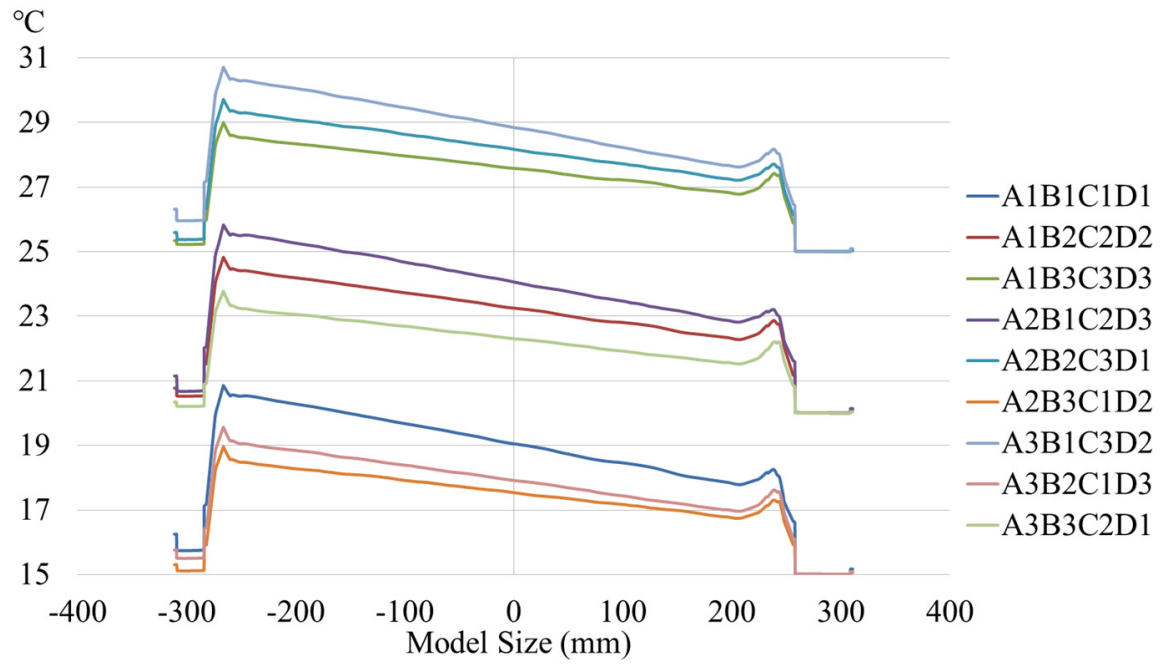

(a) L1 L9 fluid temperature distribution

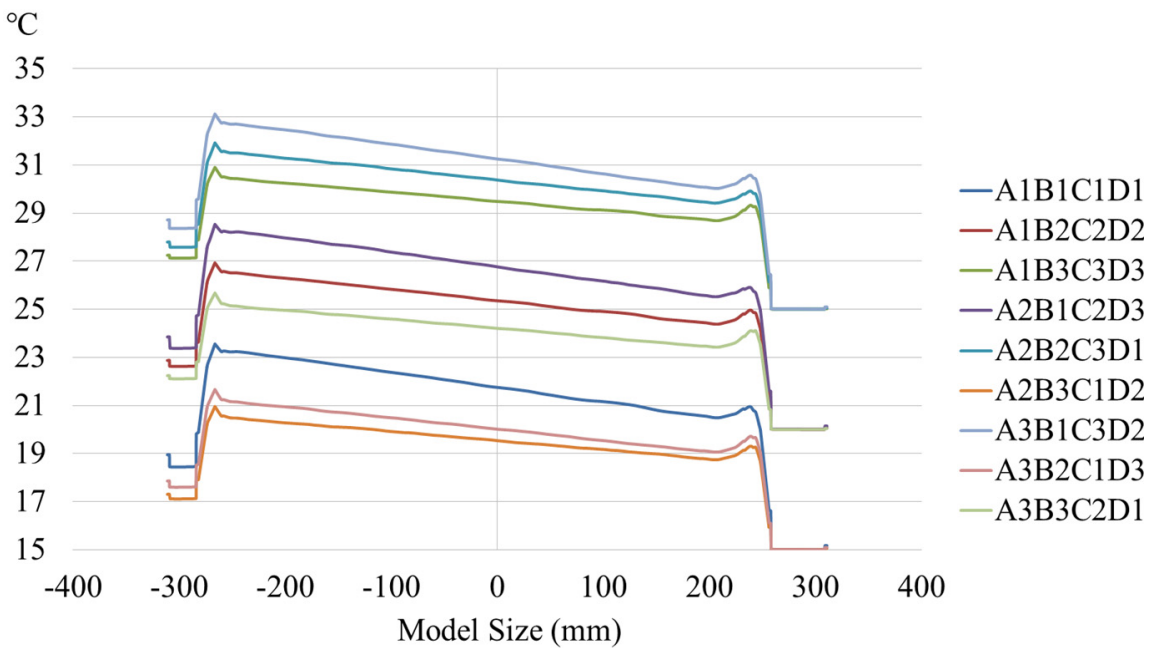

(b) L1 L9 temperature distribution

\section{$\mathrm{Pa}$}

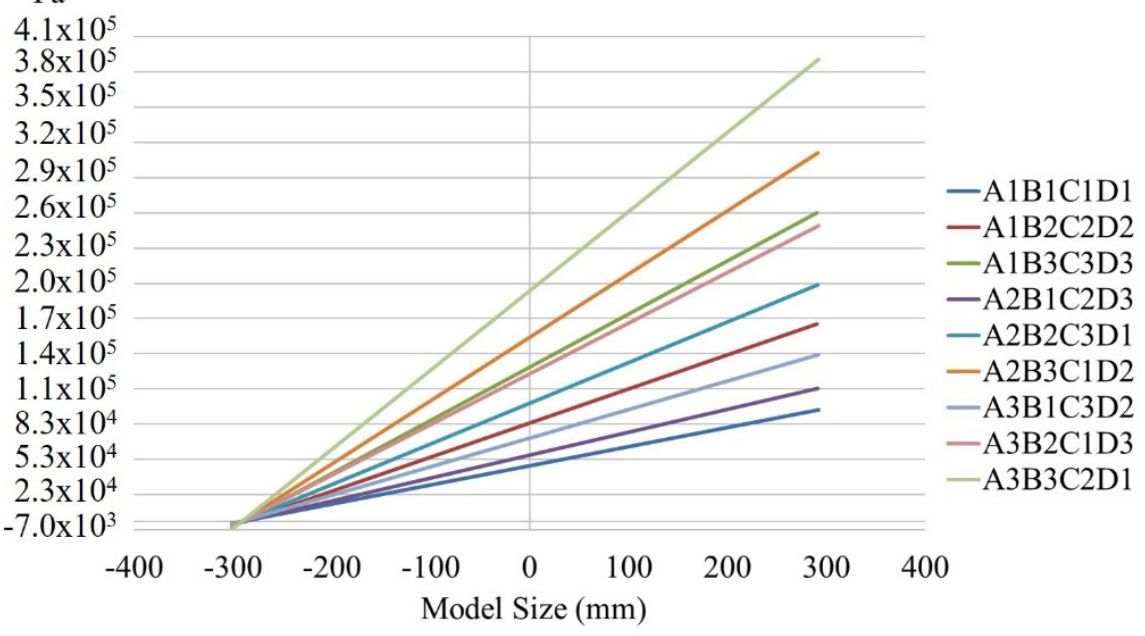

(c) L1-L9 fluid pressure distribution

Figure 9. Analysis diagram of the simulation results of the L1-L9 cold plates. 
The temperature equalization of the heat source surface of the cold plate is an important factor that affects the functional stability of the whole system. Using the temperature equalization of the heat source surface of Table 4, the average value of each factor is determined, as shown in Table 5, and the response diagram of the average value of the temperature equalization quality is shown in Figure 10. It can be seen that the optimized system performance parameter is A1B3C3, as shown in Table 4, that the horizontal parameter of factor $\mathrm{D}$ remains unchanged, that the optimization simulation result of the three-dimensional cold plate is $\mathrm{L} 3$, that the temperature equalization is $3^{\circ} \mathrm{C}$, that the fluid velocity is $6.13 \mathrm{~m} / \mathrm{s}$, and that the pressure is $149060 \mathrm{~Pa}$.

Table 5. Average of factors at three levels.

\begin{tabular}{ccccc}
\hline Quality Analysis & A & B & C & D \\
\hline Level 1 & 3.73 & 4.50 & 3.93 & 3.87 \\
Level 2 & 3.83 & 3.77 & 3.83 & 3.90 \\
Level 3 & 3.97 & 3.27 & 3.77 & 3.77 \\
\hline
\end{tabular}

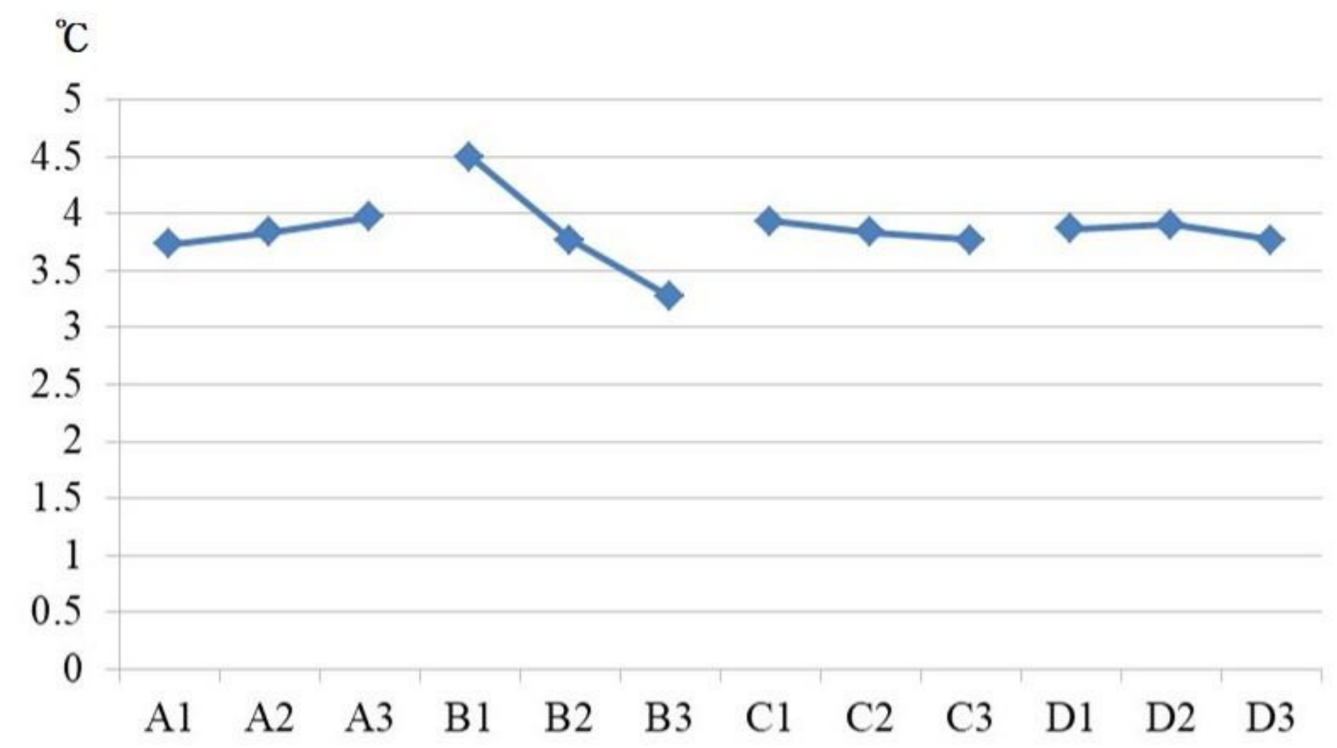

Figure 10. Average temperature quality response diagram.

\section{Experimental Verification}

\subsection{System Hardware Architecture}

This study used the designed fluid circulation heat dissipation system (as shown in Figure 1) to assemble the hardware components, as shown in Figure 11. Among them, the heat exchanger, compressor, radiator, pump, digital flow meter, and heat exchanger were purchased from the market, and the three key hardware components of the coolant storage tank, the diverter, and the QTRM were designed and manufactured for this study. The performance specifications of the hardware are shown in Table 6. The manufacturing instructions of the key hardware components are as follows: 


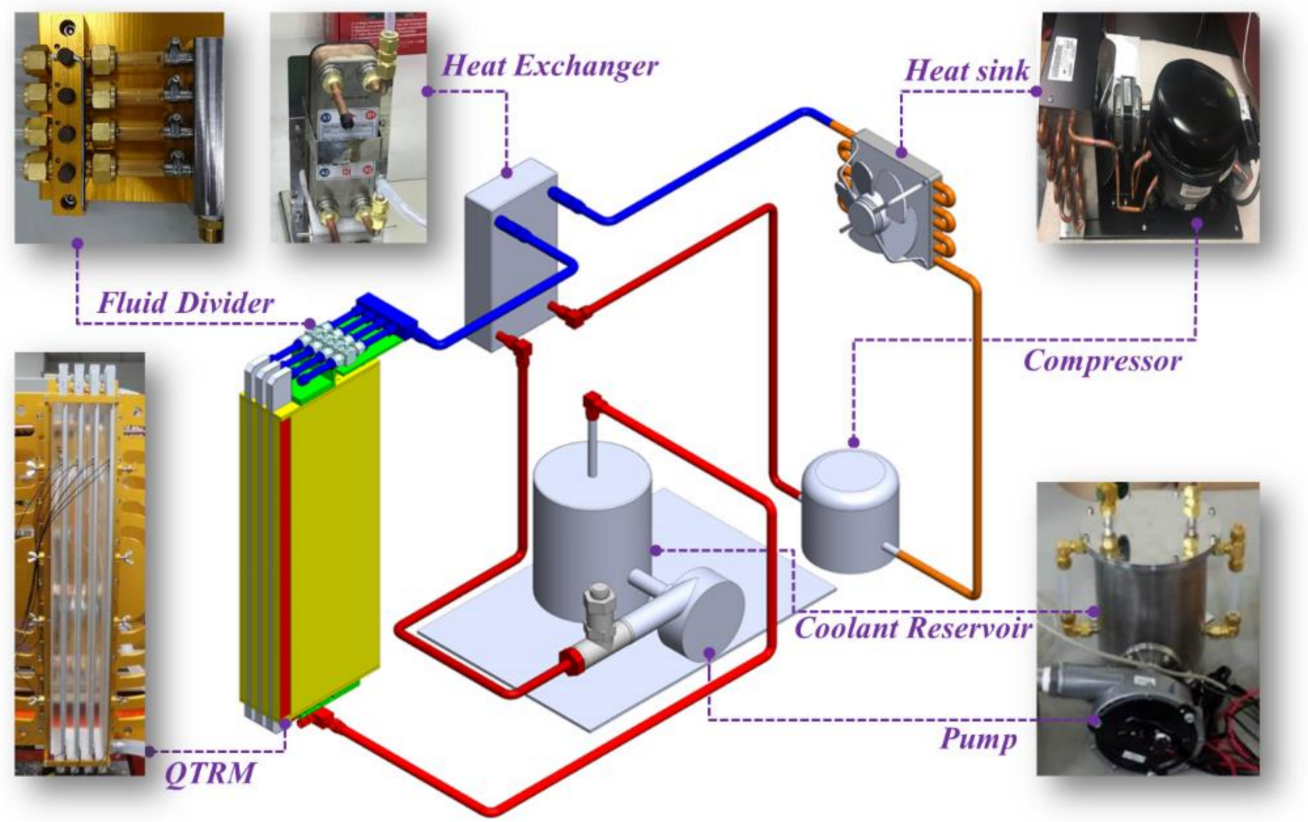

Figure 11. Hardware configuration of the fluid circulation heat dissipation system module.

Table 6. Performance specifications for each piece of hardware.

\begin{tabular}{|c|c|c|c|}
\hline $\mathrm{S} / \mathrm{n}$ & Product Name & Functions & Equipment Specifications \\
\hline 1 & $\begin{array}{l}\text { Quad transmit receive } \\
\text { module of array radar }\end{array}$ & Heat source & $\begin{array}{l}210 \mathrm{~W} \text { (single }) \times 4- \\
\text { in }=840 \mathrm{~W}\end{array}$ \\
\hline 2 & Fluid cold plate & Fast heat conduction & $\begin{array}{l}\text { Length: } 622 \mathrm{~mm} \times \text { width: } \\
40 \mathrm{~mm} \times \text { thickness: } 12 \mathrm{~mm}\end{array}$ \\
\hline 3 & Shunt & $\begin{array}{l}\text { Regulate flow rate ( } 1 \text { in and } \\
44 \text { out) }\end{array}$ & $\begin{array}{c}\text { Self-made (the outer } \\
\text { diameter of the water inlet } \\
\left.\text { is } 1 / 2^{\prime \prime}\right)\end{array}$ \\
\hline 4 & Digital tachometer & Monitor/transmit traffic & GFM-FS-20 \\
\hline 5 & Coolant reservoir & Storage/recovery of liquid & $2500 \mathrm{~mL}$ \\
\hline 6 & Heat exchanger & Coolant cooling & $\begin{array}{l}\text { Hard-welded K025 (Brazed } \\
\text { Plate Heat Exchanger) }\end{array}$ \\
\hline 7 & Radiator & Cooling & Embraco UFI12HBX-SD \\
\hline 8 & Compressor & $\begin{array}{l}\text { Provide refrigeration } \\
\text { cycle power }\end{array}$ & $\begin{array}{c}\text { Embraco FFI } 12 \mathrm{HBX}, \mathrm{DC} \\
\text { variable frequency } \\
\text { compressor } 1 / 3 \mathrm{hp}\end{array}$ \\
\hline 9 & PUMP & $\begin{array}{c}\text { Provide fluid } \\
\text { circulation power }\end{array}$ & EWP 8041 \\
\hline 10 & $\begin{array}{l}\text { Temperature sensor } \\
\text { (12EA) }\end{array}$ & $\begin{array}{l}\text { Monitor the temperature of } \\
\text { each point of the cold plate }\end{array}$ & $\begin{array}{c}\text { K_Type temperature range } \\
0^{\circ} \mathrm{C} \sim 1370^{\circ} \mathrm{C}\left( \pm 0.7^{\circ} \mathrm{C}\right)\end{array}$ \\
\hline
\end{tabular}

The fabrication of the fluid cold plate was optimized according to $\mathrm{A} 1 \mathrm{~B} 3 \mathrm{C} 3$, as obtained in Section 4.3. The aluminum alloy (6061-T6) material was selected for fabrication, according to its A1 size, and the integrated cold plate was formed by vacuum welding process bonding, as shown in Figure 12. 


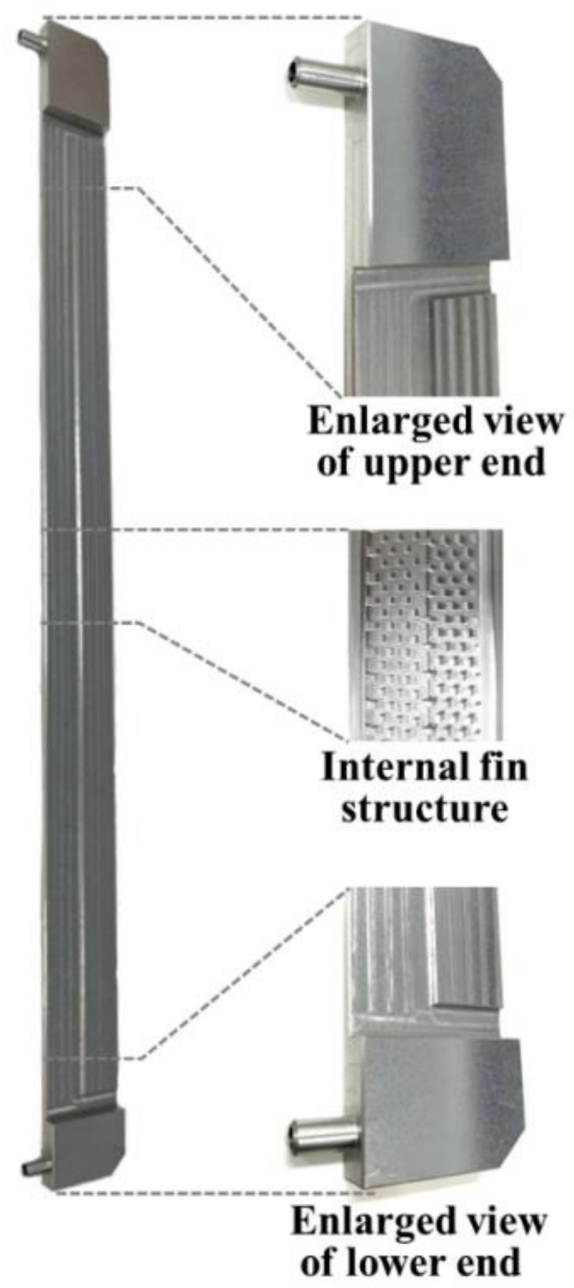

Figure 12. Hardware of the cold plate.

The main function of the shunt is to make the mass flow rate of the coolant flowing into each cold plate the same. Since there are four fluid cold plates in this system, a one-in and four-out shunt was designed for the flow control in this study. The hardware of the shunt is shown in Figure 13.

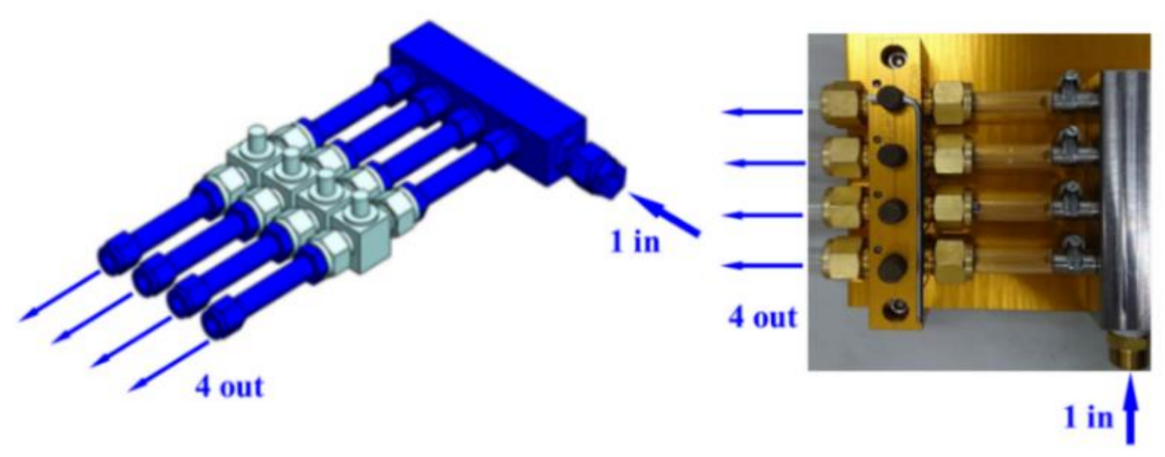

(a) Design drawings

(b) Hardware diagram

Figure 13. Shunt hardware. 


\subsection{Heat Dissipation System Experiment}

In the experimental design of this paper, a thermocouple (K-type) was connected to the junction of the cold plate and the heat source. Each cold plate was arranged with one measuring point at the upper, middle, and lower ends, respectively, and the four groups of cold plates had a total of 12 measuring points, as shown in Figure 14. They were also connected with the temperature data acquisition component to measure the temperature data in real time.

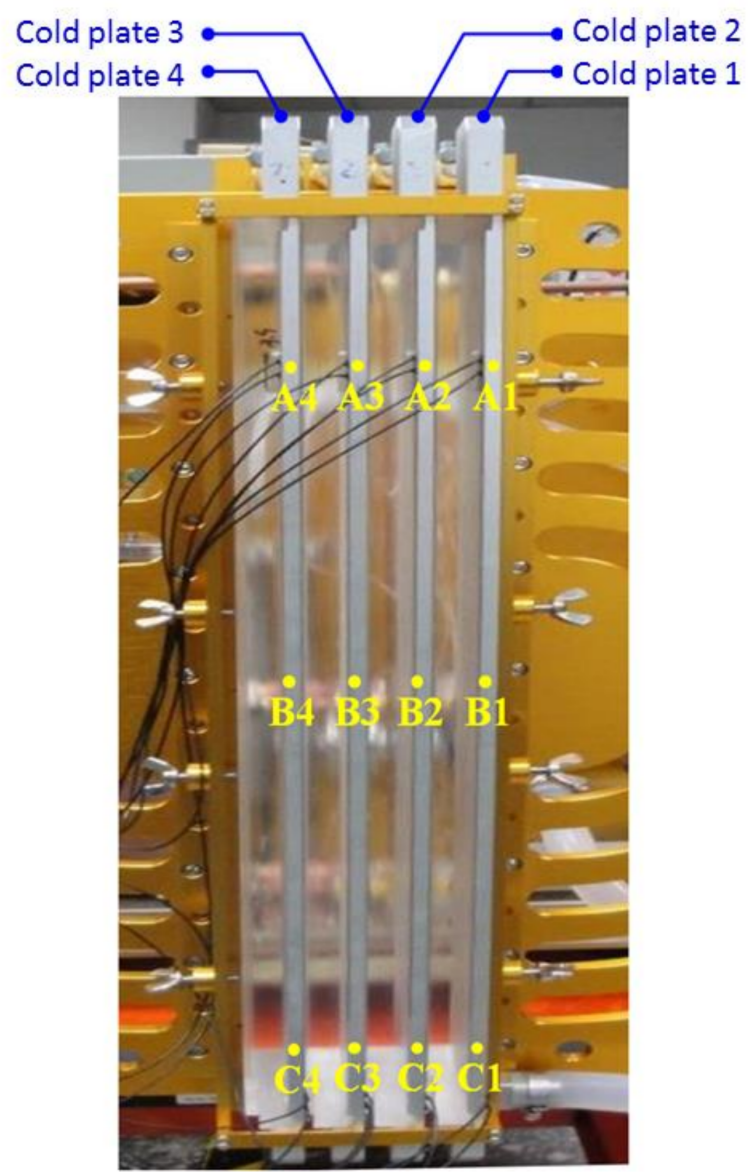

Figure 14. Location of the temperature measuring points.

The experimental time of the fluid circulation heat dissipation system was $60 \mathrm{~min}$, the coolant fluid was fluorinated liquid, the total heat source of the overall system was $840 \mathrm{~W}$, the initial temperature of the coolant was $25.6^{\circ} \mathrm{C}$, and the ambient temperature was $26.6^{\circ} \mathrm{C}$. The temperature change of each measuring point during the experiment is shown in Figure 15. The experimental results show that it takes about 35 min to enter a steady state where the system state maintains a certain fixed range and no longer changes with time. According to the observations, the maximum overall temperature was $35.8^{\circ} \mathrm{C}$ at the position of the $\mathrm{C} 2$ temperature sensor, while the minimum value was $32.4{ }^{\circ} \mathrm{C}$ at the position of the A3 temperature sensor. The temperature difference between the maximum and minimum values of the overall temperature was $3.4^{\circ} \mathrm{C}$, which is not much different from the simulation results of Exp. 3 (optimal design parameter) in Table 4 with a heat source surface temperature equalization of $3.0^{\circ} \mathrm{C}$, and meets the specification requirements (the temperature difference is $5.0^{\circ} \mathrm{C}$ ). This also proves the correctness of the results obtained in the simulation stage, as well as the reliability of the optimal design method adopted in this paper. 


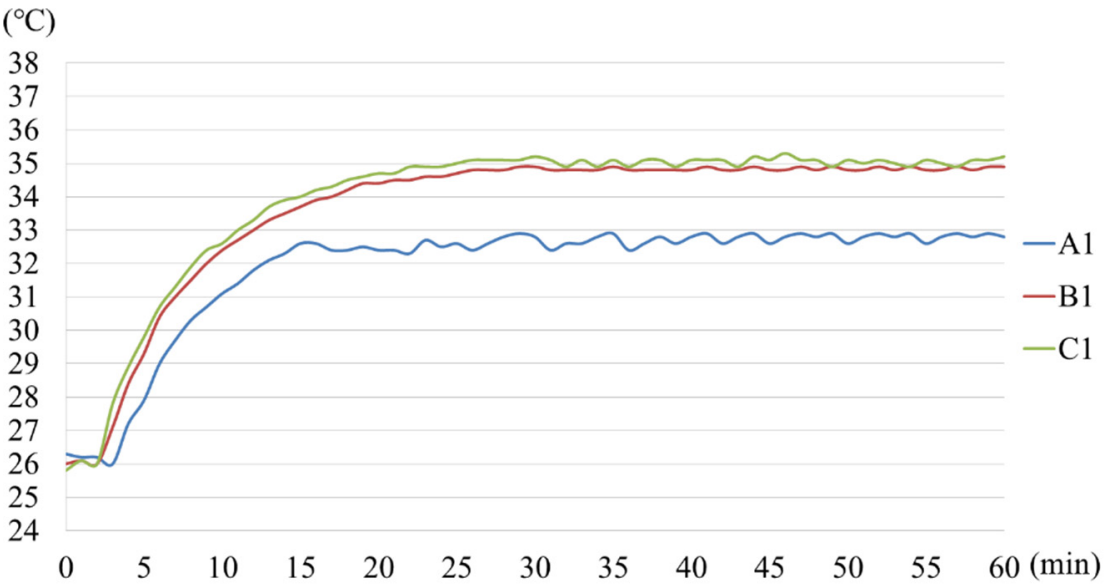

(a) Cold plate 1

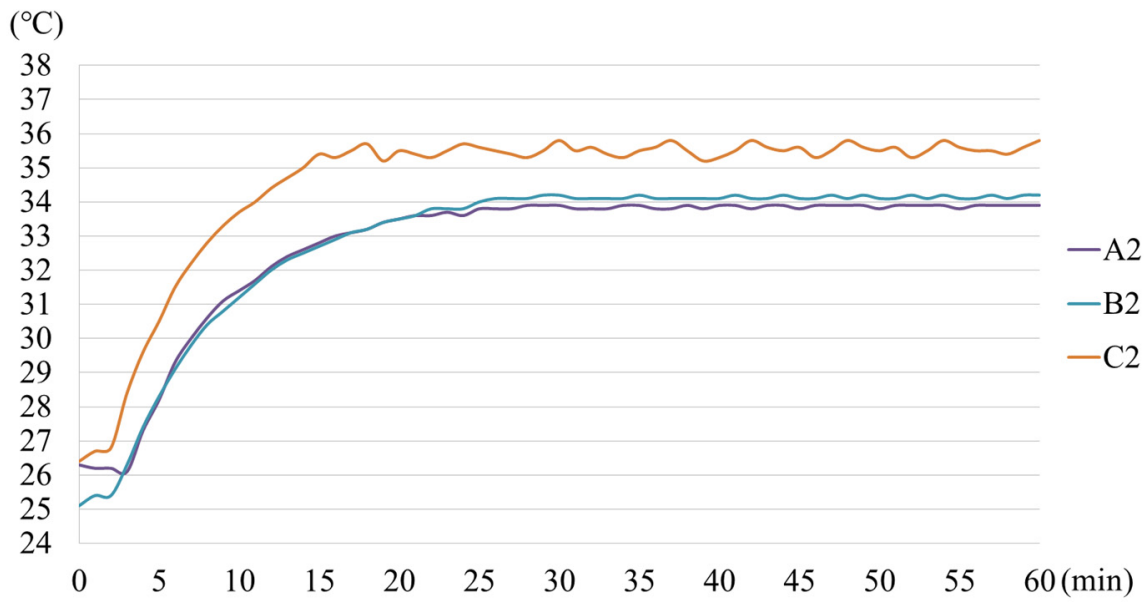

(b) Cold plate 2

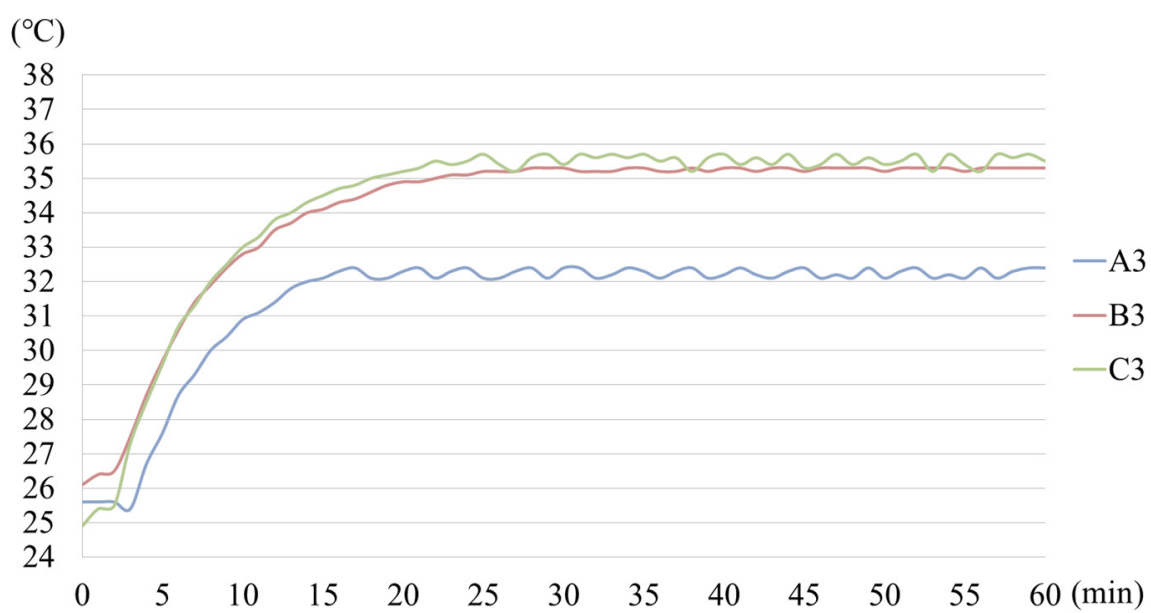

(c) Cold plate 3

Figure 15. Cont. 


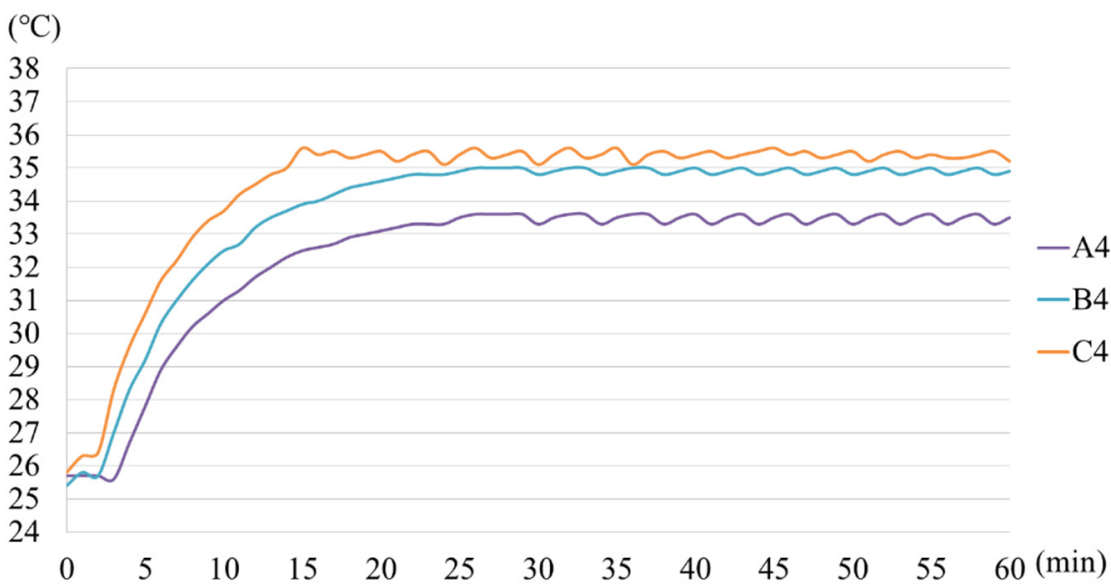

(d) Cold plate 4

Figure 15. Temperature distribution of the fluid cold plate.

\section{Conclusions}

Miniaturization and multifunctioning are the basic performances required by radar systems, while a proper heat dissipation system is a crucial mechanism for ensuring the reliability and life-span of the system. Based on the specifications of the no-load AESA radar T/R module, and a system that is limited by its size and weight, this study integrated a fluid circulation-type cold plate and array radar T/R Module to develop an integrated heat dissipation system that was suitable for high-power radar equipment. In the proposed system, the temperature equalization and heat dissipation performances of the fluid circulation-type cold plate are the key components that directly affect the radar performance. On this basis, three kinds of fluid circulation-type cold plates were designed in advance in this study. In the cold plate design, we use the simulation method and the Taguchi method to optimize the design of the parameters in the initial stage, so as to initially obtain a better design scheme for the cold plate, and then manufacture the physical samples based on the optimized design parameters to ensure that the physical samples can meet the performance requirement. This can reduce the risk of poor product performance. According to the simulation and experimental results, the proposed integrated heat dissipation mechanism can control the temperature equalization and temperature of the system within the specified requirements; thus, this system can operate within the requirements of energy saving and performance specifications. Moreover, the effectiveness and practicability of the heat dissipation mechanism, as proposed in this work, can be verified, and a reference can be provided for the design of high-power electronic equipment in a heat dissipation system. In addition, as the velocity of flow has a great influence on the heat dissipation efficiency of the three-dimensional cold plate, the factors affecting the heat dissipation performance can be seen in the research process.

The faster the flow rate, the better the heat dissipation efficiency, and the greater the relative internal pressure; however, the greater pressure may cause structural damage to the cold plate. Subsequently, the trial-produced hardware was introduced into the optimization parameters, and experiments were carried out to determine the balance between the flow rate and the pressure, which can make the operating system more stable and reliable.

Author Contributions: Conceptualization, Data curation, Formal analysis, Investigation, Methodology, Project administration, Visualization, Writing—original draft, J.-Y.L. and Y.-L.L.; Resources, Software, Validation, J.-Y.L.; Supervision, Writing-review and editing, Y.-L.L., S.-W.M. and M.-D.T. All authors have read and agreed to the published version of the manuscript.

Funding: This research was funded by Electronic Systems Research Division, National Chung-Shan Institute of Science and Technology of Taiwan, R.O.C., under Grant No. 09163P-CS. 
Institutional Review Board Statement: Not applicable.

Informed Consent Statement: Not applicable.

Data Availability Statement: The datasets used and analyzed during the current study are available from the corresponding author on request.

Acknowledgments: We appreciate the financial support of the National Chung-Shan Institute of Science \& Technology and suggestions on the research directions.

Conflicts of Interest: The authors declare no conflict of interest.

\section{References}

1. Wiriyasart, S.; Naphon, P. Liquid impingement cooling of cold plate heat sink with different fin configurations: High heat flux applications. Int. J. Heat Mass Transfer. 2019, 140, 281-292. [CrossRef]

2. Wiriyasart, S.; Naphon, P. Heat spreading of liquid jet impingement cooling of cold plate heat sink with different fin shapes. Case Stud. Therm. Eng. 2020, 20, 100638. [CrossRef]

3. Zhang, H.; Li, C.; Zhang, R.; Lin, Y.; Fang, H. Thermal analysis of a 6s4p Lithium-ion battery pack cooled by cold plates based on a multi-domain modeling framework. Appl. Therm. Eng. 2020, 173, 115216. [CrossRef]

4. Ho, J.Y.; Leong, K.C. Cylindrical porous inserts for enhancing the thermal and hydraulic performance of water-cooled cold plates. Appl. Therm. Eng. 2017, 121, 863-878. [CrossRef]

5. Xu, X.; Tong, G.; Li, R. Numerical study and optimizing on cold plate splitter for lithium battery thermal management system. Appl.Therm. Eng. 2020, 167, 114787. [CrossRef]

6. Deng, T.; Zhang, G.; Ran, Y. Study on thermal management of rectangular Li-ion battery with serpentine-channel cold plate. Int. J. Heat Mass Transfer. 2018, 125, 143-152. [CrossRef]

7. Deng, T.; Zhang, G.; Ran, Y.; Liu, P. Thermal performance of lithium ion battery pack by using cold plate. Appl. Therm. Eng. 2019, 160, 114088. [CrossRef]

8. Jarrett, A.; Kim, Y. Design optimization of electric vehicle battery cooling plates for thermal performance. J. Power Sources 2011, 196, 10359-10368. [CrossRef]

9. Jarrett, A.; Kim, I.Y. Influence of operating conditions on the optimum design of electric vehicle battery cooling plates. J. Power Sources 2014, 245, 644-655. [CrossRef]

10. Huo, Y.; Rao, Z.; Liu, X.; Zhao, J. Investigation of power battery thermal management by using mini-channel cold plate. Energy Convers. Manag. 2015, 89, 387-395. [CrossRef]

11. Cova, P.; Delmonte, N.; Giuliani, F.; Citterio, M.; Latorre, S.; Lazzaroni, M.; Lanza, A. Thermal optimization of water heat sink for power converters with tight thermal constraints. Microelectron. Reliab. 2013, 53, 1760-1765. [CrossRef]

12. Cova, P.; Delmonte, N.; Chiozzi, D.; Portesine, M.; Vaccaro, F.; Mantegazza, E. Water cold plates for high power converters: A software tool for easy optimized design. Microelectron. Reliab. 2018, 88-90, 801-805. [CrossRef]

13. Cova, P.; Santoro, D.; Spaggiari, D.; Portesine, F.; Vaccaro, F.; Delmonte, N. CFD modeling of additive manufacturing liquid cold plates for more reliable power press-pack assemblie. Microelectron. Reliab. 2020, 114, 113734. [CrossRef]

14. Cao, J.; He, Y.; Feng, J.; Lin, S.; Ling, Z.; Zhang, Z.; Fang, X. Mini-channel cold plate with nano phase change material emulsion for Li-ion battery under high-rate discharge. Appl. Energy 2020, 279, 115808. [CrossRef]

15. Li, X.; Zhou, D.; Zhang, G.; Wang, C.; Lin, R.; Zhong, Z. Experimental investigation of the thermal performance of silicon cold plate for battery thermal management system. Appl. Therm. Eng. 2019, 155, 331-340. [CrossRef]

16. Zhang, Q.; Ye, H.; Wang, Z.J. A comparative study of launch canister thermal control systems using a liquid or gas working medium. Appl. Therm. Eng. 2018, 131, 125-131. [CrossRef]

17. Frazier, W.E. Metal additive manufacturing: A review. J. Mater. Eng. Perform. 2014, 23, 1917-1928. [CrossRef]

18. Fletcher, K.K.; Sparks, T.E.; Flood, A.; Liou, F. A SOA approach to improve performance of metal additive manufacturing simulation. In Proceedings of the 2017 IEEE International Conference on Cognitive Computing (ICCC), Honolulu, HI, USA, 25-30 June 2017; pp. 140-143.

19. Lin, S.L.; Lin, C.C.; Lin, D.Y.; Chuang, C.S. Laser additive manufacturing technology in titanium 64 implant of microstructure fabrication and analysis. In Proceedings of the 8th Annual IEEE International Conference on Nano/Micro Engineered and Molecular Systems, Suzhou, China, 7-10 April 2013; pp. 594-597.

20. Yan, Y.; Ding, C.; Ngo, K.D.T.; Mei, Y.; Lu, G. Additive manufacturing of planar inductor for power electronics applications. In Proceedings of the International Symposium on 3D Power Electronics Integration and Manufacturing (3D-PEIM), Raleigh, NC, USA, 13-15 June 2016; pp. 1-16.

21. Yuan, L. Solidification defects in additive manufactured materials. JOM 2019, 71, 3221-3222. [CrossRef]

22. Wang, D.; Wang, Z.; Li, K.; Ma, J.; Liu, W.; Shen, Z. Cracking in laser additively manufactured W: Initiation mechanism and a suppression approach by alloying. Mater. Des. 2019, 162, 384-393. [CrossRef]

23. Kim, F.H.; Moylan, S.P. Literature review of metal additive manufacturing defects. NIST Adv. Manuf. Ser. 2018, 100-116. [CrossRef] 
24. Riemer, A.; Richard, H.A. Crack propagation in additive manufactured materials and structures. Procedia Struct. Integr. 2016, 2, 1229-1236. [CrossRef]

25. Kandilikar, S.G.; Hayner, C.N. Liquid cooled cold plates for industrial high-power electronic devices-Thermal design and manufacturing considerations. Heat Transfer. Eng. 2009, 30, 918-930. [CrossRef]

26. Kosar, A.; Peles, Y. Thermal-hydraulic performance of MEMS-based pin fin heat sink. J. Heat Transf. 2006, 128, 121-131. [CrossRef]

27. Manglik, R.M.; Bergles, A.E. Heat transfer and pressure drop correlations for twisted-tape inserts in isothermal tubes: Part I-Laminar Flows. J. Heat Transf. 1993, 115, 881-889. [CrossRef]

28. Vanapalli, S.; ter Brake, H.J.M.; Jansen, H.V.; Burger, J.F.; Holland, H.J.; Veenstra, T.T.; Elwenspoek, M.C. Pressure drop of laminar gas flows in a microchannel containing various pillar matrices. J. Micromech. Microeng. 2007, 17, 1381-1386. [CrossRef]

29. Lee, Y.J.; Lee, P.S.; Chou, S.K. Enhanced thermal transport in microchannel using oblique fins. J. Heat Transf. 2012, 134, 101901-1-101901-10. [CrossRef]

30. Boomsma, K.; Poulikakos, D.; Zwick, F. Metal foams as compact high performance heat exchangers. Mech. Mater. 2003, 35, 1161-1176. [CrossRef]

31. Wirtz, R.A.; Xu, J.; Park, J.W.; Ruch, D. Thermal/fluid characteristics of 3-D woven mesh structures as heat exchanger surfaces. IEEE Trans. Comp. Packag. Technol. 2003, 26, 40-47. [CrossRef]

32. Boomsma, K.; Poulikakos, D. On the effective thermal conductivity of a threedimensionally structured fluid-saturated metal foam. Int. J. Heat Mass Transf. 2000, 44, 827-836. [CrossRef]

33. Dai, Z.; Nawaz, K.; Park, Y.G.; Bock, J.; Jacobi, A.M. Correcting and extending the Boomsma-Poulikakos effective thermal conductivity model for three-dimensional, fluid saturated metal foams. Int. Commun. Heat Mass Transf. 2010, 37, 575-580. [CrossRef]

34. Yang, H.; Zhao, M.; Gu, Z.L.; Jin, L.W.; Chai, J.C. A further discussion on the effective thermal conductivity of metal foam: An improved model. Int. J. Heat Mass Transf. 2015, 86, 207-211. [CrossRef]

35. Wong, M.; Owen, I.; Sutcliffe, C.J.; Puri, A. Convective heat transfer and pressure losses across novel heat sinks fabricated by selective laser melting. Int. J. Heat Mass Transf. 2009, 52, 281-288. [CrossRef]

36. Ho, J.Y.; Wong, K.K.; Leong, K.C. Saturated pool boiling of FC-72 from enhanced surfaces produced by selective laser melting. Int. J. Heat Mass Transf. 2016, 99, 107-121. [CrossRef]

37. Yu, G.; Xiong, L.; Du, C.; Chen, H. Simplified model and performance analysis for top insulated metal ceiling radiant cooling panels with serpentine tube arrangement. Case Stud. Therm. Eng. 2018, 11, 35-42. [CrossRef]

38. Wang, Z.; Ye, H. Parametric analysis of the thermal shielding performance of a cold plate with a serpentine flow design. In ASTFE Digital Library; Begel House Inc.: Fort Lauderdale, FL, USA, 2018.

39. Yang, F.; Lin, Y.; Wei, X.; Ye, H. Infrared suppression of a power-generation cabin with a cold plate system. Appl. Therm. Eng. 2019, 158, 113820. [CrossRef] 